\title{
Development of a South African integrated syndromic respiratory disease guideline for primary care
}

\author{
*René G Englisha,b, Eric D Batemanc, Merrick F Zwarenstein ${ }^{\mathrm{a}, \mathrm{d}}$, Lara R Fairalla,c, \\ Angeni Bheekiee, Max O Bachmann ${ }^{\text {a,f }}$, Bosielo Majara ${ }^{\mathrm{g}}$, Salah-Eddine Ottmanin, \\ Robert W Scherpbieri
}

a Knowledge Translation Unit, University of Cape Town Lung Institute, Cape Town, South Africa
${ }^{\text {b }}$ Department of Public Health and Family Medicine, University of Cape Town, South Africa
${ }^{c}$ Division of Pulmonology, Department of Medicine, University of Cape Town, South Africa
${ }^{d}$ Department of Health Policy, Management and Evaluation, University of Toronto, Ontario, Canada
e School of Pharmacy, University of Western Cape, Cape Town, South Africa
${ }^{f}$ Health Services Reseach, Department of Health Policy and Practice, University of East Anglia, Norwich, UK
${ }^{g}$ Formerly of the Department of Community Health, University of the Free State, Bloemfontein, South Africa
${ }^{\text {h }}$ The Practical Approach to Lung Health, Stop TB, World Health Organisation, Geneva, Switzerland
${ }^{\text {i }}$ Formerly of the The Practical Approach to Lung Health, Stop TB, World Health Organisation, Geneva, Switzerland

Received 16th January 2008; revised 28th March 2008; accepted 22nd May 2008; online 13th August 2008

\begin{abstract}
Aims: The Practical Approach to Lung Health in South Africa (PALSA) initiative almed to develop an integrated symptom- and sign-based (syndromic) respiratory disease guideline for nurse care practitionęrs working in primary care in a developing country.

Methods: A multidisciplinary team developed the guideline after revewing local barriers to respiratory health care provision, relevant health care policies, existing respiratory guidelines, andliterature. Guideline drafts were evaluated by means of focus group discussions. Existing evidence-based guideline development methodologies were tailored for development of the guideline.

Results: A locally-applicable guideline based on syndromic diagnostic algorithms was developed for the management of patients 15 years and older who presented to primary carefacilities with cough or difficulty breathing.

Conclusions: PALSA has developed a guideline that integrates and presents diagnostic and management recommendations for priority respiratory diseases in adults using a symptom- and sign-based algorithmic guideline for nurses in developing countries.

(C) 2008 General Practice Airways Group. All rights reserved.

R English et al. Prim Care Resp J 2008; 17(3): 156-163.

doi:10.3132/pcrj.2008.00044
\end{abstract}

Keywords guideline, diagnosis, primary care, nurse, asthma, COPD, tuberculosis, infection, management

See linked editorial by Rashidian on page 136

See Appendix A at www.thepcrj.org

\section{Introduction}

Over the past few decades there has been an increase in the application of evidence-based methodologies for the development of globally accessible disease-specific respiratory guidelines. ${ }^{1,2}$ In parallel, however, a lesser-known approach to developing guidelines, mainly for resource-poor settings, has also emerged. ${ }^{3,4}$ In the latter, key diagnostic and management recommendations for a number of related respiratory conditions are tailored to the local setting and are integrated into a single guideline through the use of algorithms. More recently, integrated - as opposed to disease-specific - guidelines, have also been developed for use in resource-rich settings..$^{5-7}$

The Practical Approach to Lung Health in South Africa (PALSA) initiative is a local adaptation and expansion of the

\footnotetext{
* Corresponding author: Dr Rene English, Department of Public Health and Family Medicine, University of Cape Town, 4th Floor, Falmouth Building, Health Sciences Medical Faculty, Anzio Road, Observatory Cape Town, 8000 South Africa. Tel: +27 (0)82967 9585 E-mail: renglish@pgwc.gov.za
} 
World Health Organisation's (WHO) Practical Approach to Lung Health (PAL) strategy. ${ }^{8-10}$ PALSA aims to strengthen the health system through the implementation of locally applicable integrated symptom- and sign-based (syndromic) algorithms for the detection and management of respiratory disease conditions in primary care. The rationale for this approach is that, particularly in developing countries, approximately one-third of patients presenting to primary care facilities have respiratory symptoms. ${ }^{11,12}$ Furthermore, these facilities, whilst geared to identify patients that might have tuberculosis, are often ill-resourced for making other respiratory diagnoses or for treating common diseases such as asthma, chronic obstructive pulmonary disease (COPD), or even pneumonia. ${ }^{11}$ In several developing countries, including South Africa, primary health care (PHC) nurses are the frontline clinicians in many if not most state-sponsored facilities, and they are required to make the initial assessment and provide treatment. Typically, access to doctors is limited, with most such contacts requiring referral by the nurse. In rural areas, such referrals may be delayed by weeks. It is therefore essential that nurses are equipped to make diagnoses, to perform initial investigations albeit within the constraints of local capacities and resources, to identify patients requiring emergency care or immediate referral to the next level of care, and/or to commence appropriate initial treatment. Developing guidelines to equip nurses to perform these tasks in this setting is indeed challenging, as many recommendations proposed in best practice guidelines are based on very different practice environments and profiles of disease, and assume the availability of more diagnostic resources and treatments. Moreover, skills sets and levels may be different. ${ }^{13}$

We describe here the development of the PALSA guideline, highlighting the developmental approach which was adopted, in an attempt to ensure that the guideline and its accompanying package of interventions were both, as far as possible, evidence-based yet practical, with the potential for improving the quality of care offered to patients presenting with respiratory symptoms to primary health care facilities in South Africa. The intervention comprises a syndromic diagnostic algorithm, supporting educational materials, and a programme of educational outreach for primary care nurses provided by trained supervisors. ${ }^{10}$

\section{Methods}

\section{Formation of a guideline development group}

A multidisciplinary guideline development group was formed, comprising a pulmonologist, public health specialists and researchers, primary care clinicians, and a pharmacist. The group's primary purpose was to determine the end-users and the target population, to review relevant existing policies, documents and guidelines, to provide feedback on the drafts of the gutdeline, and to review feedback on the guideline itself. Table $\uparrow$ provides an outline of the development processes. At the first meeting, the aims of the guideline, the proposed development process, the roles and responsibilities of each member, and the methods to be employed were discussed. The group adapted and applied known guideline development theories and frameworks to the process of

Table 1. Table indicating time frames of the guideline development process.

\begin{tabular}{|c|c|c|c|c|c|c|c|c|}
\hline \multirow[t]{2}{*}{ Guideline development phase } & \multirow{2}{*}{$\begin{array}{c}2001 \\
\text { Sept- Dec }\end{array}$} & \multicolumn{4}{|c|}{2002} & \multicolumn{3}{|c|}{2003} \\
\hline & & Jan-Mar & Apr-Jun & Jul-Sep & Oct-Dec & Jan-Mar & Apr-Jun & Jul-Sep \\
\hline Review of PAL guideline* & & & & & & & & \\
\hline $\begin{array}{l}\text { Review of policies, guidelines, } \\
\text { and literature* }\end{array}$ & & & & & & & & \\
\hline Brainstorming* & & & & & & & & \\
\hline Focus group discussions** & & & & & & & & \\
\hline Face-to-face interviews ${ }^{* * *}$ & & & & & & & & \\
\hline PALSA Guideline development**** & & & & & & & & \\
\hline $\begin{array}{l}\text { Development of materials } \\
\text { and training* }\end{array}$ & & & & & & & & \\
\hline Pilot of PALSA intervention* & & & & & & & & \\
\hline
\end{tabular}

* Guideline development group $(n=6) ; * *$ Comprising doctors and nurses $(n=40) ; * * *$ Comprising representatives from the provincial and national department $(n=2)$, as well as pulmonologists $(n=5) ; * * * *$ Guideline development group with RGE as the lead guideline developer. 
guideline and intervention package development. ${ }^{14-16}$ Identification of barriers and facilitators to care

Theories of changing professional practice and guideline development emphasise the importance of developing a guideline that is tailored to address locally-identified barriers to care. ${ }^{17-19}$ Thus, through review of the literature, a series of focus group discussions, and one-on-one interviews, both the barriers and facilitators to care were identified and were considered during the development of the guideline and the support materials. The purpose of this process was to provide insight into the type and magnitude of the challenges faced by primary care staff, and whether or not these were related to access to resources or to knowledge about appropriate diagnosis and care of respiratory conditions.

\section{Review of relevant local policies}

To ensure local applicability, national policies and documents outlining primary care provision in South Africa were reviewed in order to establish the strategies and frameworks for primary health care implementation. The vehicle for delivery of primary health care in South Africa is by means of the District Health System. ${ }^{20}$ Furthermore, organisational logistics relating to the District Health System, such as referral patterns and management structures, were also reviewed. Norms and standards for human and physical resource availability at health facilities as well as the role and scope of practice of primary health care nurses were assessed. The South African Essential Drug List (EDL) provided a framework for medicines to be included in the guideline. ${ }^{13}$ The decision on the number and nature of clinical diagnoses to be induded was based on published reports on the prevalence of diseases in the region, and on the advice of local experts and nurse practitioners regarding the respiratory conditions that posed the greatest problem to them in their daily practice.

Review of relevant international and local guidelines The first stage of development involved a thorough evaluation of the PAL guideline by the guideline development group and by a group of PHC nurses, doctors, and managers, through a series of focus group discussions. Particular attention was paid to the guideline layout, its local applicability and user-friendliness, and the content and treatment recommendations. International and local respiratory guidelines were reviewed to determine key treatment and management recommendations based on available evidence for the range of diseases to be included in the guideline. Research publications were also reviewed, as were published systematic reviews. Finally, local PHC guidelines were assessed to determine the extent to which they complied with the aforementioned guidelines.

\section{Review of the medical literature}

Published literature profiling local epidemiological disease patterns, as well as studies on the diagnosis and management of relevant respiratory conditions, were reviewed. The development group chose not to conduct their own systematic reviews because of resource and time constraints, but instead consulted existing systematic reviews. Articles were identified through electronic searching and through hand searching of retrieved articles.

\section{Assimilation of research evidence and recommendations into the guideline}

As a first step, the guideline development group agreed on the overall concept, layout, presentation and content of the PAL guideline. Suggestions on how it could be adapted were elicited. Prior to the first focus group session, the lead guideline developer compiled a draft version of the PALSA guideline using the steps reported above. At the outset, it was decided that the guideline would take the form of algorithms and would assume that the diagnosis of the patient was not known at presentation. This was done to mimic everyday clinical practice whereby patients often present with signs and symptoms and not pre-defined diagnoses. Using this approach as the framework, evidencebased diagnostic and treatment recommendations were used to develop the Salgorithms. The feasibility of these recommendations for the local setting was assessed by determining, whether or not the diagnostic equipment, medieations, and referral patterns or outpatient management strategies were applicable. Particular attention was paid to whether nurses were trained to recognise, diagnose, and treat the conditions to be included in the guideline. Any deviations from the identified evidence-based recommendations - such as the absence of spirometry in primary health care facilities, or limitations on ipratropium bromide prescribing to COPD patients in primary care - were flagged and accounted for during the development process. Where these deviations could not be corrected or improved upon, substitutions or changes in management - such as instructing the nurse to refer the patient to a higher level for further management - were made. The paucity of diagnostic equipment and skill sets in primary care facilities led to the guideline being primarily syndromic in nature. The initial draft was then revised after focus group discussions with frontline workers and managers. The PALSA guideline development was thus an iterative process. Figure 1 illustrates how the combination of the various development methods served to inform the development of the guideline, its support materials, and the training strategy.

\section{Review and revision of draft versions of the PALSA} guideline

The first focus group session was considered to be the exploratory phase of the development process. The generic PAL guideline was reviewed and discussed, and the recommendations for its adaptation were presented. This process also served to identify the barriers to the delivery of 
Figure 1. Illustration of methods used to develop the PALSA guideline and support materials.

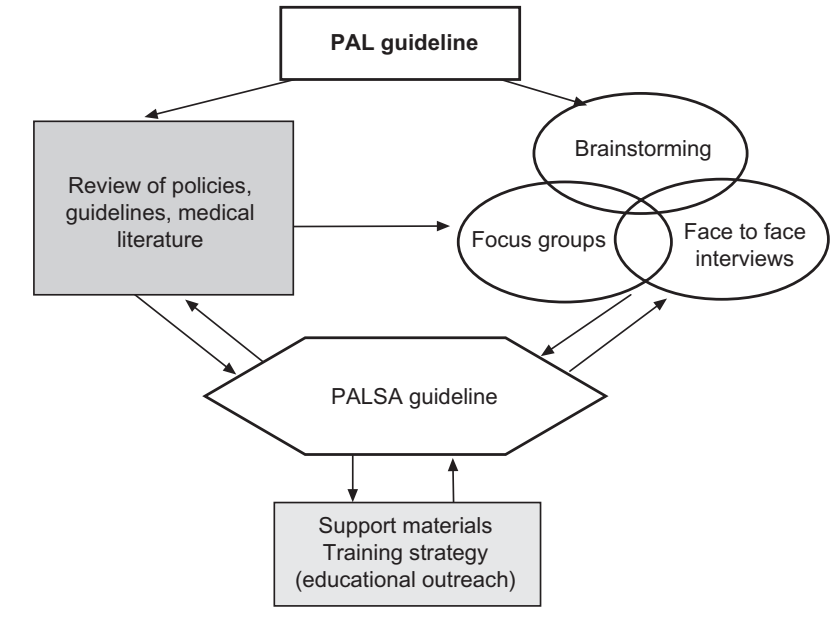

quality respiratory disease care, and to inform the first draft of the PALSA guideline and its support materials. At a second focus group in the Free State province, the first draft of the PALSA guideline was appraised for its content, layout, local applicability, and user-friendliness. Based on feedback from this meeting the guideline was revised and further changes were made in consultation with nurses, managers andother key roleplayers, particularly concerning treatment recommendations. A second focus group was held to view the revised version and to discuss proposals for the development of support materials and a training strategy. Based on this feedback, the guideline development group developed support materials and a training intervention strategy. ${ }^{10}$ Three further focus group discussions were held to pilot the intervention.

\section{Results}

\section{Guideline concept}

The PALSA guideline was developed for nurses working in primary care clinics. It targets patients 15 years or older who present with cough or difficult breathing.

The guideline had a number of underlying objectives. Firstly, as mentioned previously, it took into account resource availability and considered that most primary care nurses were not trained to perform detailed physical examinations or to interpret chest radiographs. Other respiratory diagnostic services such as spirometry, skin prick testing, and blood gas analysis, are not available in primary care. Secondly, being syndromic in nature it was designed to follow a logical diagnostic sequence with respect to the main presenting symptoms (see Figure 2). Furthermore, the time of onset of itlness (acate versus chronic) and symptom clusters (constellation of symptoms or signs predicting a condition) were used to guide the diagnosis of a specific disease or a dinical syndrome. Acute diseases or presentations were located in the first part of the guideline. Thirdly, treatment

Figure 2. Figure illustrating flow of PALSA guideline

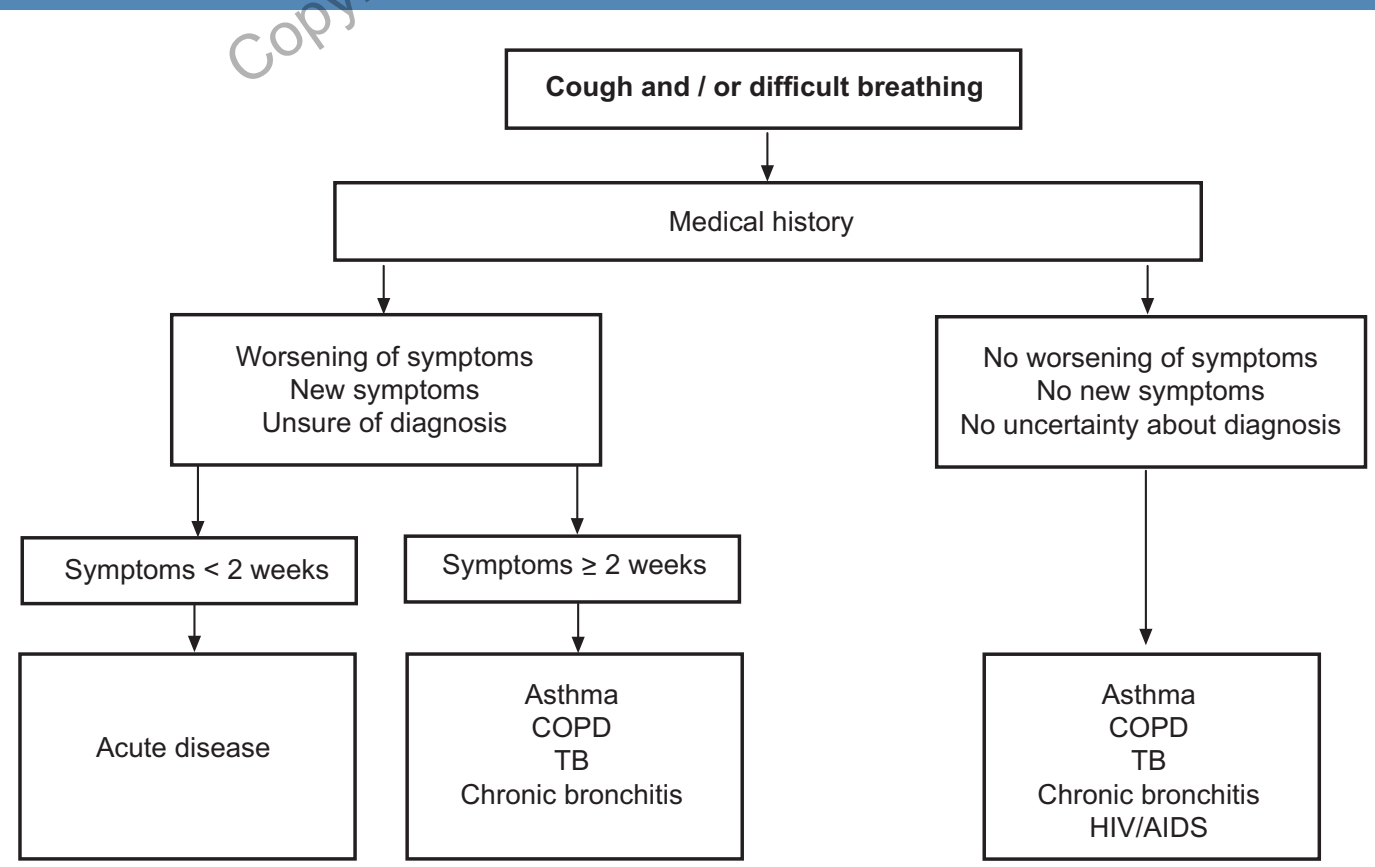


recommendations were tailored to treat the most likely diagnosis, but referral to the next level of care was recommended if there was diagnostic uncertainty or if further treatment was required by a doctor or specialist. Finally, the guideline also allowed for multiple diagnoses to be made at the same visit; for example, the algorithms allowed for a patient presenting with an acute exacerbation of asthma to be assessed also for the severity of the underlying chronic respiratory condition and for the frequency and type of follow-up and long-term management. Multiple pathologies at a single diagnosis is a common finding in primary care, but is often neglected in single-disease guidelines; an example of how this was addressed was that in the case of tuberculosis (TB) diagnosis, the user was encouraged to suspect TB in all patients, thus encouraging increased case finding - this being particularly important in South Africa in view of the high prevalence of TB.

Figure 3. Figure illustrating pages 12 and 13 of the guideline

\section{DIAGNOSING OBSTRUCTIVE LUNG DISEASE}

It is not always easy to decide whether a patient has asthma or COPD as the symptoms may be similar, or both diseases may be present. A few questions may help with diagnosis.

Ask if:

- Symptoms started during childhood or early adulthood

- History of hayfever, eczema and/or allergies

- Family history of asthma

- Symptoms only during attacks with periods of normal breathing in between

- Symptoms are usually worse: at night; in the early hours of the morning; during an upper respiratory tract infection or when the weather changes.

- Symptoms improve or disappear afer using inhaler

\section{Y \\ TREAT AS ASTHMA REFER TO DOCTOR WITHIN 1 MONTH \\ Go to page 13}

Ask if:

- Symptoms started later in life (usually after the age of 35 years)

- Symptoms slowly worsened over a long period of time

- Long history of daily or frequent cough and sputum production (usually starts long before the onset of shortness of breath)

- Short of breath for most of the day, rather than at night or during the early hours of the morning only

- History of heavy smoking, e.g. more than 20 cigarettes / day for 15 years or more

\section{(If insure, treat as asthma)}

If $\leq 1$ feature of asthma, and no significant history of smoking, considen a cardiac or non-lung cause of breathlessness, especially if associated hypertension, ischaemic heart disease and/or diabetes mellitus,

\section{MANAGEMENT OF CHRONIC ASTHMA}

The aim of asthma management is to obtain complete control of all features of asthma.

Aim for: 1. Minimal (ideally no) daytime and night time symptoms

2. Minimal or no exacerbations (asthma attacks)

3. Minimal needfor quick-relief medications

4. No limitations for daily activities

Assess control of asthma by asking about day and night time symptoms

\begin{tabular}{|c|c|c|c|}
\hline Level of control & Well-controlled & Moderate control & Poor control \\
\hline $\begin{array}{l}\text { Daytime symptoms per week } \\
\text { Night time symptoms per month }\end{array}$ & $\begin{array}{l}<2 \text { times / week } \\
<2 \text { times / month }\end{array}$ & $\begin{array}{l}\text { 2-4 times / week } \\
\text { 2-4 times / month }\end{array}$ & $\begin{array}{l}\text { Continuous } \\
\text { Frequent }\end{array}$ \\
\hline Levels of treatment & Low (if well-controlled) & Moderate (if moderate control) & Maximum (if poor control) \\
\hline Inhaled salbutamol & 2 puffs when needed & 2 puffs when needed & $\begin{array}{l}2 \text { puffs when needed } \\
\text { May be required 4-6 times per day }\end{array}$ \\
\hline Inhaled corticosteroids & 200-400 micrograms / day & 800 micrograms / day & 800-1600 micrograms / day \\
\hline $\begin{array}{l}\text { Slow-release theophylline } \\
\text { - Doctor to initiate }\end{array}$ & - & - & 1 tablet twice a day \\
\hline Oral prednisone & - & - & $\begin{array}{l}40 \mathrm{mg} \text { orally (once daily) for } \\
14 \text { days to gain rapid control }\end{array}$ \\
\hline
\end{tabular}

\section{REVIEW EVERY 3 MONTHS}

If complete control at any level of treatment

- Continue current medication

- At next visit, reduce treatment to previous level (step-down) if control is still complete

- Schedule next appointment
If poor control at any level of treatment

- Increase to next level of treatment (step-up)

- Consider adding prednisone $40 \mathrm{mg}$ orally once daily for 7 days and reassess in 1 month

Refer if poor control despite stepping-up 
The guideline was presented in the form of a high-quality colour, A4, ring-bound booklet. An excerpt from the guideline is presented in Figure 3 , and the whole guideline is available as Appendix A at www.thepcrj.org.

\section{Guideline content}

The diseases included in the guideline were asthma, chronic obstructive pulmonary disease (COPD), TB and respiratory tract infections. Deviations from what would be considered normal practice were that no attempt was made to distinguish between asthma and COPD during acute presentations of these conditions. Instead, the management was syndromic. Attempts to distinguish between them were only made when the long-term management plan was being formulated using the guideline. The most commonly seen respiratory tract infections were also included. Specific emphasis was placed on assisting the user to make a distinction between upper and lower tract infections - a difficulty that is commonly encountered in clinical practice in the absence of radiography. Further, as requested by the focus groups participants, colour pictures of mouth and ear lesions were also included. The diagnostic and treatment approaches to chronic presentations of both asthma and COPD were based solely on symptoms and signs to compensate for the absence of diagnostic equipment in primary care. The diagnostic and treatment algorithms for $\mathrm{TB}$ were those of the South African National Tuberculosis Control Programme, simplified for ease of use within the context of treating potential co-morbidity. The guideline alsolcontained sections for Voluntary Counselling and Testing for HIV infection, and basic care of patients infected with HIV, including the diagnosis of opportunisistic infections and the provision of cotrimoxazole prophylaxis. It did not contain details of anti-retroviral therapy as the roll-out of this treatment for HIVIAIDS had not commenced in South Africa.

\section{Disaussion}

The PALSA guideline provides an example of the successful development and implementation of a locally-adapted guideline that is tailored to the local context. Its development has partly met a subsequent call for the development and implementation of integrated global guidelines for primary care in developing settings. ${ }^{21}$ Further, the guideline also supports the possibility of integrating common respiratory conditions into a single guideline using a symptom- and signbased algorithmic approach to the diagnosis and management of patients through the application of various theoretical and research techniques.

The performance of the PALSA guideline was subsequently tested in two studies. In the first, the ability of a nurse using the guideline to correctly diagnose a respiratory disease or disease syndrome was tested against that of a physician with access to special investigations. These results demonstrated that the sensitivity and specificity of the guideline in the hands of the nurse for suspecting TB $(n=1400)$ was $76 \%(95 \% \mathrm{Cl}: 71 \%-79 \%)$ and $77 \%(95 \% \mathrm{Cl}$ : $74 \%-79 \%)$, respectively. ${ }^{8}$ For diagnosing TB $(n=320)$, the estimates were $90 \%$ (95\% Cl: 76\%-97\%) and 65\% (95\% Cl: $63 \%-68 \%)$, with a negative predictive value of $99 \%(98 \%$ $100 \%)$. The guideline also performed well at detecting the remaining conditions (unpublished data). The second study was a pragmatic cluster randomised controlled study to evaluate the guideline's effect at improving respiratory care. ${ }^{9}$ This study confirmed an increase in the case detection of TB in the intervention clinics (6.4\% versus 3.8\%; OR: 1.72 (95\% Cl: 1.04-2.85) and a higher rate of prescriptions for inhaled corticosteroids (13.7\% versus $7.7 \% ; 1.90$ (1.14-3.18) $(n=1999)$.

Furthermore, the development methods used also provide an approach to guideline adaptation for resource-poor settings. These methods lelosely resemble those recently proposed by the ADAPTE group for the development of multicomponent lifterventions, ${ }^{22,23}$ and for the development of complex interventions. ${ }^{24}$ They differ, however, to those used by most international guideline development groups for usualevidence-based best practice guidelines. ${ }^{14-16}$ One of the main ways in which it differs from that of evidence-based development methods is in the area of reviewing and opresenting the supporting available evidence. Typically, a large amount of resources are required to conduct extensive systematic reviews. However, the PALSA guideline development group relied more on secondary research, such as published systematic reviews, which by their nature include results obtained from different countries and patient pools. Furthermore, the evidence-based recommendations were considered as best practice by the guideline developers but were not included as recommendations if they were considered not to be applicable to the local setting. Grading of the evidence was also not included in the guideline. Similarities to the methodologies proposed by international guideline development groups are that the development group was multidisciplinary in nature, ${ }^{25}$ and that the topic and focus of the guideline was determined prior to its development, with the subject area being defined by the level of care at which it would be targeted as well as to the enduser. ${ }^{21,26,27}$ Finally, the guideline underwent extensive external review before its finalisation and implementation.

The strength of the development process is that the guideline development group was comprised of members with a wide range of experiences, interests and skills. Furthermore, to achieve ownership and to promote implementation of the guideline, emphasis was placed on the involvement of primary care staff and higher level 
management during the development process.

Ensuring adherence to local policies, and consideration of resource capacity and availability in the public sector was intentional, and served to ensure that when the guideline was used in the facilities it would be entirely appropriate. Through the process of identifying barriers to care, the development group was able to tailor the guideline and the intervention materials to address those barriers which were identified as being changeable. For example, the guideline contained numerous prompts to test for TB in patients presenting with cough for two or more weeks - since it was identified through the focus group discussions that many nurses were not regarding patients with these symptoms as being tuberculosis suspects. Another example was that, although cotrimoxazole was freely available in the public sector, it was not being prescribed for HIV-infected patients who met the criteria for receiving them prophylactically. This management strategy was thus included in the guideline. Through consultation with management and within the context of evaluation of the intervention, nurses were allowed to initiate inhaled corticosteroid treatment for newly-diagnosed asthmatics, a practice that was previously only permitted for doctors. ${ }^{9}$ These approaches served to support the implementation of research findings into practice. ${ }^{28}$

Limitations to the development process were the limited range of medications that could be included in the guidelipe, as well as the absence of diagnostic equipment such as spirometers, and the limited skill sets of the nurse practitioners. As indicated previously, these barriers were overcome by tailoring the guideline, to the locabsetting and ensuring that appropriate management steps were recommended where possibte. Ideally, the development group would have liked to have consulted more widely with primary care staff during the guideline's development phases but this was not feasible from a cost and time perspective. Qualitative research conducted alongside the evaluation of the intervention strategy shows that the guideline suited the practices and resource availability in primary care (unpublished reports). This suggests that the initial focus group discussions captured what was necessary to inform the development process. For subsequent expansion of the guideline, the development group formed larger guideline development teams comprising representatives from the public health management and lower level health sectors, as well as academics and researchers in the relevant fields.

In PALSA there is also emphasis on the practicality of treatment recommendations and on the prioritisation of treating common diseases. For this purpose, the experience and local knowledge of managers and of practitioners (including physicians, nurses, pharmacists) is often pivotal in determining which course to follow at each decision and treatment node. For the diagnostic algorithms, the shortcomings in testing each decision node were diminished by ensuring that the decisions were deliberately biased toward the diagnosis of conditions that should not be missed (higher sensitivity) at the expense of specificity, and to ensure that in such circumstances the guideline provides for earlier referral to the next level of care where the diagnosis and treatment could be reviewed. For example, when in doubt between asthma and COPD, the diagnostic algorithm recommended a syndromic diagnosis of asthma and commencement (if uncontrolled) of low dose inhaled corticosteroids. But the programme requires that in such circumstances a physician reviews the diagnosis within one month.

From a public health perspective, the success of the guideline is evidenced by the very favourable response from users and managers. Even before the study results were analysed, requests were received from both Provincial and the National Departments of Health to expand the content of the guideline to include the nurse's role in the monitoring and follow-up of patients commenced on anti-retroviral therapy. The PALSA intervention strategy, including the guideline, was subsequently rolled out for implementation in two provinces in South Africa, and is to be implemented nationally in the Chear future. Since its initial development, the PALSA guideline has been revised annually and is now called PALSAPlus Obecause of the inclusion of the management of HIV/AIDS and sexually transmitted infections.

\section{Condusion}

The PALSA guideline provides an example of a locally developed guideline adapted to suit the local context and to meet identified needs. It also provides an example of the importance of using guideline development techniques that have been adapted to suit local resources and priorities.

\section{Conflicts of interest declaration}

No conflicts of interest declared.

\section{Acknowledgements}

We thank the staff of the Free State University's Community Health Department, the Free State Department of Health, and Annatjie Peters in assisting with, and participating in, the focus group discussions; Dr Rifiloe Matjie and the South African National Tuberculosis Control Programme; Dr Rod Dawson, Dr Agnes Hurter, Professor Neil White, Professor Gillian Ainslie for reviewing drafts of the PALSA guideline; Michael Wyeth for the layout of the PALSA guideline and support materials; and the WHO Stop TB department.

\section{Editors' acknowledgement}

The PALSA Guideline, previously published as 'Additional File 1 ' in the BMC paper http://www.biomedcentral.com/content/pdf/1471-2466-6-22.pdf has been duplicated in its entirety as Appendix A, available online at www.thepcrj.org, with the kind permission of the original publisher and the authors, in order for the guideline material to reach a wider audience. 


\section{Copyright GPIAG - reproduction prohibited}

\section{References}

1. Global strategy for asthma management and prevention. NIH publication No 02-3659. Available from: http://www.ginasthma.org.

2. Global strategy for the diagnosis, management, and prevention of COPD. Executive summary. Available from: http://www.goldcopd.com/.

3. World Health Organization. Practical Approach to Lung Health (PAL): a primary health-care strategy for the integrated management of respiratory conditions in people five years of age or over. Geneva: World Health Organization; 2005. (WHO/HTM/TB/2005.352).

4. The Practical Approach to Lung Health. Available from: http://www.who.int/tb/dots/pal/en/index.html.

5. van Schayck $C P$, Levy ML, Stephenson P, Sheikh A. The IPCRG guidelines: developing guidelines for managing chronic respiratory diseases in primary care. Prim Care Resp J 2006;15:1-4. doi:10.1016/j.pcrj.2005.12.003

6. The International Primary Care Airways Group (IPAG). Diagnosis and management handbook. Chronic airways diseases: A guide for the primary care physician. Jan 2005. MCR Vision Inc. url: http://www.ipagguide.org.

7. Irwin RS, Baumann MH, Bolser DC, et al. Diagnosis and management of cough executive summary. ACCP evidence-based clinical practice guidelines. Chest 2006;129:1s-23s. DOI 10.1378/chest.129.1_suppl.1S

8. English RG, Bachmann MO, Bateman ED, et al. Diagnostic accuracy of an integrated respiratory guideline in identifying patients with respiratory symptoms requiring screening for pulmonary tuberculosis: a cross-sectional study. BMC Pulmonary Medicine 2006,6:22. doi:10.1186/1471-2466-6-22.

9. Fairall LR, Zwarenstein M, Bateman ED, et al. Effect of education outreach to nurses on tuberculosis case detection and primary care of respiratory illness: pragmatic cluster randomised controlled trial. BMJ 2005;331:750-4.

10. Bheekie A, Buskens I, Allen S, et al. The Practical Approach to Lung Health in South Africa (PALSA) intervention: respiratory guideline implementation for nurse trainers. International Nursing Review 2006;53:261-8.

11. Ottmani SE, Scherpbier R, Chaulet P, Pio A, van Beneden C, Raviglione. Respiratory care in primary care services - a survey in 9 countries. Geneva World Health Organisation; 2004.

12. Bourne DE, Bloom DE, Sayed AR. The morbidity spectrum seen by general practitioners in South Africa. S Afr Med J 1991:80(10):513-14.

13. Standard Treatment Guidelines and Essential(Drugs List for South Africa. South
African National Department of Health. 2nd ed. Pretoria, South Africa:1998.

14. SIGN (Scottish Intercollegiate Guidelines Network) [homepage on the internet] Available from: http://www.sign.ac.uk/.

15. NICE (National Institute for Clinical Excellence) [homepage on the internet] Available from: http://www.nice.org.uk/.

16. NZGG (New Zealand Guidelines Group). [homepage on the internet] Available from: http://www.nzgg.org.nz/.

17. Grimshaw JM, Shirran L, Thomas R, et al. Changing provider behavior: an overview of systematic reviews of interventions. Med Care 2001;39:II2-45.

18. Conroy M, Shannon W. Clinical guidelines: their implementation in general practice. Brit J Gen Pract 1995;45:371-5.

19. Baker R, Hearnshaw H, Cheater F, et al. Tailored interventions to overcome identified barriers to change: effects on professional practice and health care outcomes. Cochrane Database Sys Rev 2005;Jul20;(3): CD 005470.

20. White paper for the transformation of the health system in South Africa. Available from: http://www.polity.org.za/html/govdocs/white_papers/ health.html? rebookmark=1.

21. Bousquet J, Grouse L. Global integrated guidelines are needed for respiratory diseases. Prim Care Resp J 2006;15:10-12. doi:10.1016/j.pcrj.2005.12.002

22. Fevers B, Burgers JS, Haugh MC, et al. Adaptation of clinical guidelines: literature review and proposition for a framework and procedure. Int I Qual Health Care 2006;18(3):167-76.

23. The APADTE Working Group [homepage on the Internet] Available from: http://www.adapte.erg.

24. Medical Researsh Council. A framework for development and evaluation of RCTs for complex interventions to improve health. Available from: http://mww.mrc.ac.uk/pdf-mrc_cpr.pdf.

25. Shekell PG Woolf SH, Eccles M, Grimshaw J. Developing guidelines. BMJ 1999:318:593-6.

26. Wôff SH. Practice guidelines: a new reality in medicine. II Methods of developing guidelines. Arch Intern Med 1992;152:946-52.

27. Eccles M, Clapp Z, Grimshaw J, et al. North of England evidence-based guideline development project: methods of guideline development. BMJ 1996;312(7033):760-2.

28. Garner $\mathrm{P}$, Kale R, Dickson R, et al. Getting research findings into practice. Implementing research findings in developing countries. BMJ 1998;317:531-5.

\section{Available online at http://www.theprj.org}




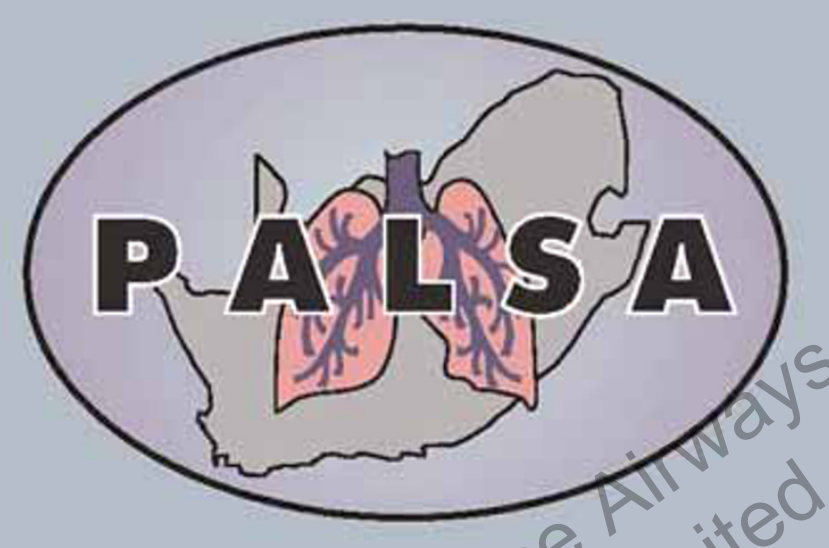

\section{PRACTICAL APPROACH TOLUNG HEALTH IN SOUTH AFRICA (PARSA) GUIDELINES}

First-Level Primary Care Management of Respiratory Diseases

Approach to the adult patient who presents with difficult breathing and/or cough. 


\section{CONTENTS}

\section{PATIENT WITH DIFFICULT BREATHING AND/OR COUGH}

Classify according to symptoms

Symptoms < 2 weeks: ASSESSMENT AND INITIAL MANAGEMENT

Further treatment of the wheezing patient: ASTHMA/COPD EXACERBATION

Discharge plan for the wheezing patient who has responded to treatment

Further treatment of the patient with fever and/or pain on breathing and coughing: LOWER RESPIRATORY TRACT INFECTION

\section{UPPER RESPIRATORY TRACT INFECTIONS}

\section{Mildly ill patient with runny/blocked nose: RHINITIS}

Mildly ill patient with pain and/or tenderness over sinuses: ACUTE SINUSITIS

Mildly ill patient with sore throat: ACUTE PHARYNGITIS, TONSILLITIS, ORAL CANDIDA 5

Mildly ill patient with sore throat: ACUTE PHARYNGITIS, TONSILLITIS, ORAL
Mildly ill patient with ear problem: ACUTE AND CHRONIC EAR PROBLEMS

Dry mopping the ear

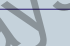

3

\section{SYMPTOMS $\geq 2$ WEEKS}

Diagnosing obstructive lung disease

Management of chronic asthma

Management of chronic obstructive pulmonary disease (COPD)

Chronic cough with or without sputum production; no breathlessness: CHRONIC BRONCHITIS

\section{TUBERCULOSIS (TB)}

\section{Diagnosing TB}

Sputum results

\section{HIV/AIDS}

Suspecting HIV/AIDS 
Cough AND/OR

\section{CLASSIFY ACCORDING TO SYMPTOMS}

Difficult breathing (defined as breathlessness at rest or on activity, wheeze and/or tight chest)

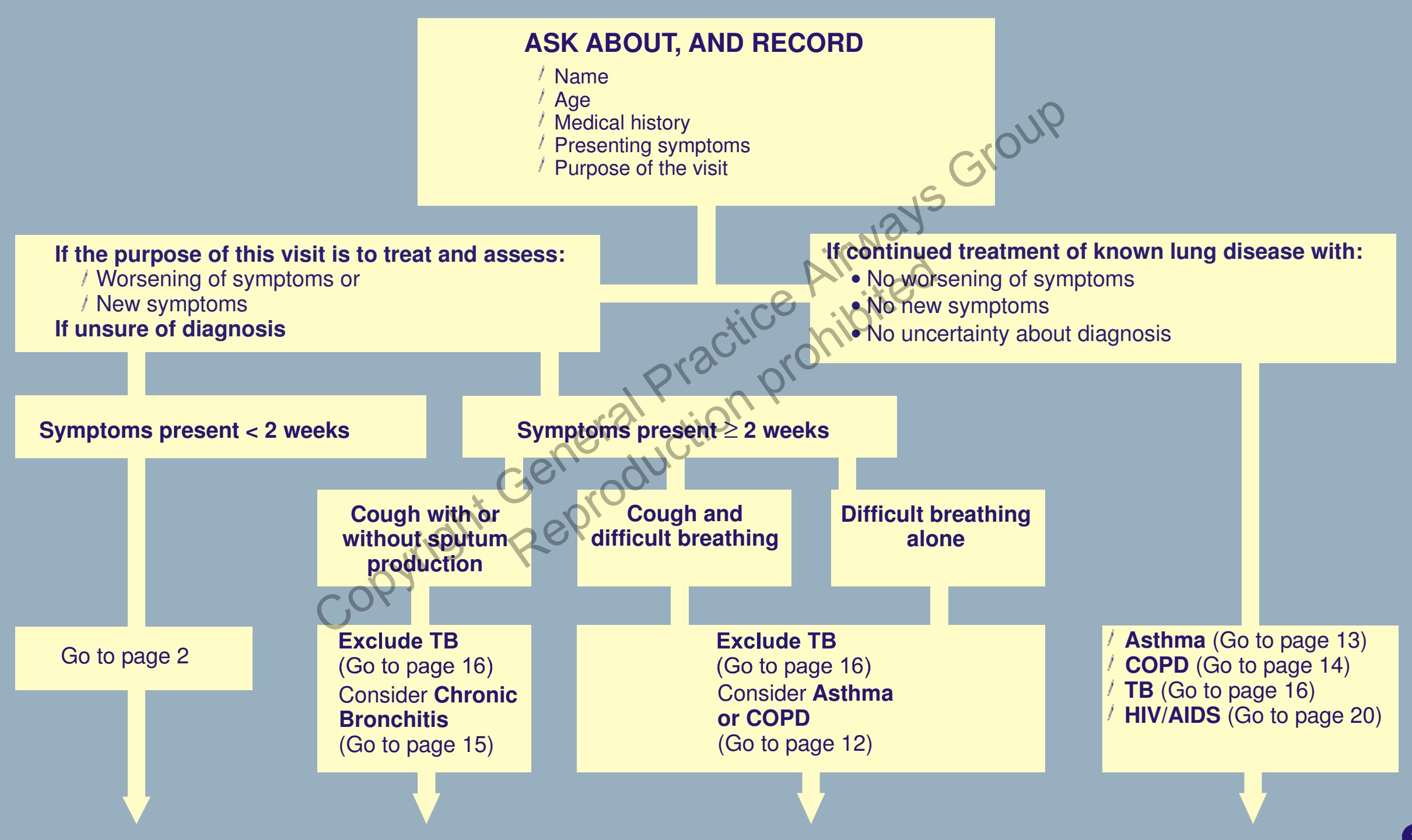

Classify according to symptoms

SYMPTOMS < 2 WEEKS 


\section{SYMPTOMS < 2 WEEKS: ASSESSMENT AND INITIAL MANAGEMENT}

\section{IF ONE OR MORE SYMPTOMS PRESENT, ASSESS SEVERITY}

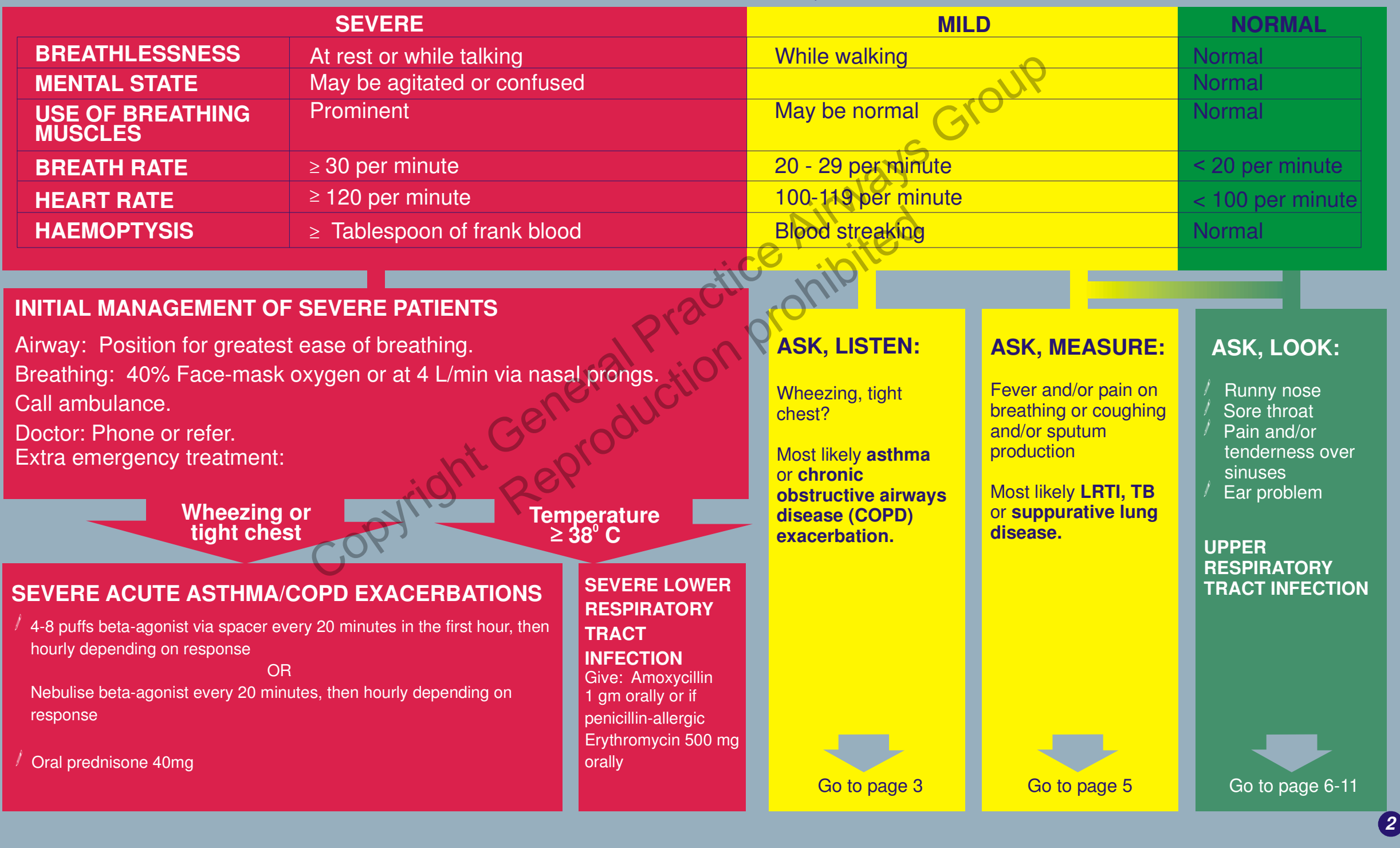




\section{FURTHER TREATMENT OF THE WHEEZING PATIENT: ACUTE ASTHMA/COPD EXACERBATION}

- 4 puffs beta-agonist via spacer every 20 minutes for one hour then reassess.

OR

Nebulise using beta-agonist every 20 minutes for one hour then reassess.

- Give 1 dose of oral prednisone $40 \mathrm{mg}$ stat.

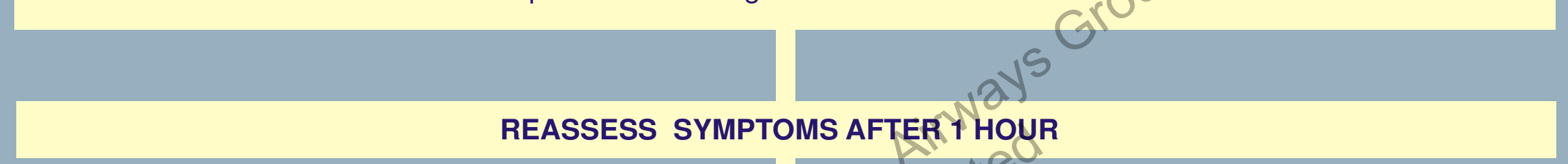

BETTER OR NO SYMPTOMS

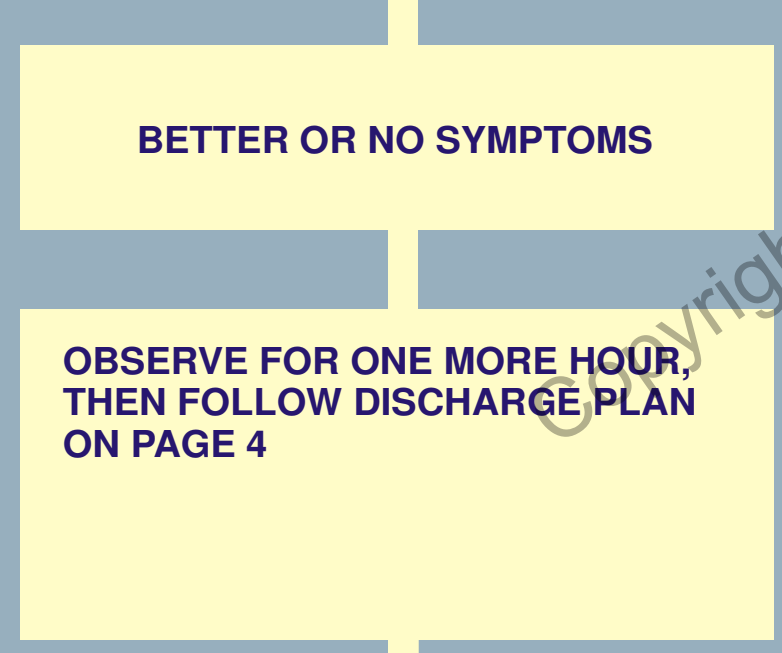

Assessment and initial management Wheezing

SYMPTOMS < 2 WEEKS

\section{REASSESS SYMPTOMS AFTER 1 HOUR}

\section{REPEAT ABOVE TREATMENT AND} ASSESS WITHIN ONE HOUR

If worsening of symptoms, treat as severe and refer.

If no response within two hours, refer.

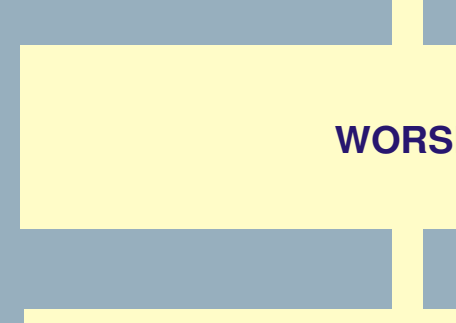

FOLLOW TREATMENT PLAN FOR SEVERE PATIENT ON PAGE 2. 


\section{DISCHARGE PLAN FOR THE WHEEZING PATIENT WHO HAS RESPONDED TO TREATMENT}

-Increase the dose and frequency of the inhaled bronchodilator to a maximum of 2 puffs 4 times a day.

-If the patient is already on inhaled corticosteroids: check compliance (are medications taken twice a day, every day)

: check inhaler technique (are the inhalers used correctly)

- If poor compliance and/or technique instruct patient on correct drug usage.

- Give 40mg of prednisone orally (once daily) for 7 days to patients with the following:

-History of recent emergency visits for asthma.

-Worsening of asthma symptoms in the months or weeks prior the onset of the acute attack.

-History of previous hospital or intensive care unit admission for asthma.

- If the patient reports a cough with new or increased sputum production and/or change in sputum colour (yellow, green) and/or fever, add Amoxycillin 500mg three times a day for 7 days OR if penicillin-allergic, Erythromycin $500 \mathrm{mg}$ four times a day for 7 days.

-If the underlying lung condition is unknown, go to page 12 to make diagnosis.

-Encourage all patients to stop smoking cigarettes, pipes or dagga.

-Book follow-up visit before medicines are expectedto run out.

\section{TELL PATIENT TO RETURN IF:}

-Symptoms get worse.

- Not better after a course of oralprednisone has been completed. 


\section{FURTHER TREATMENT OF THE PATIENT WITH FEVER AND/OR PAIN ON BREATHING OR COUGHING: LOWER RESPIRATORY TRACT INFECTION}

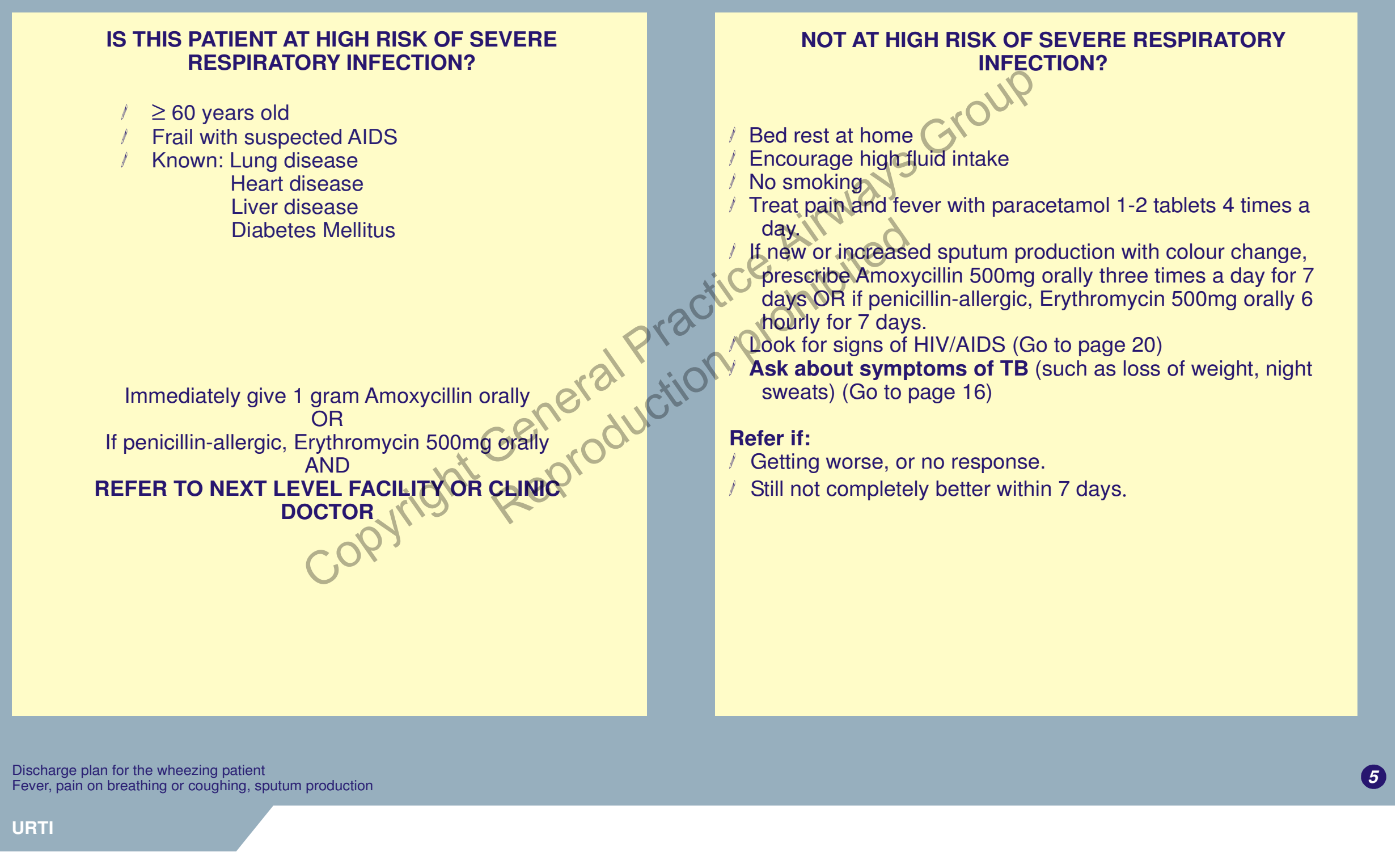




\section{MILDLY ILL PATIENT WITH RUNNY/BLOCKED NOSE: RHINITIS}

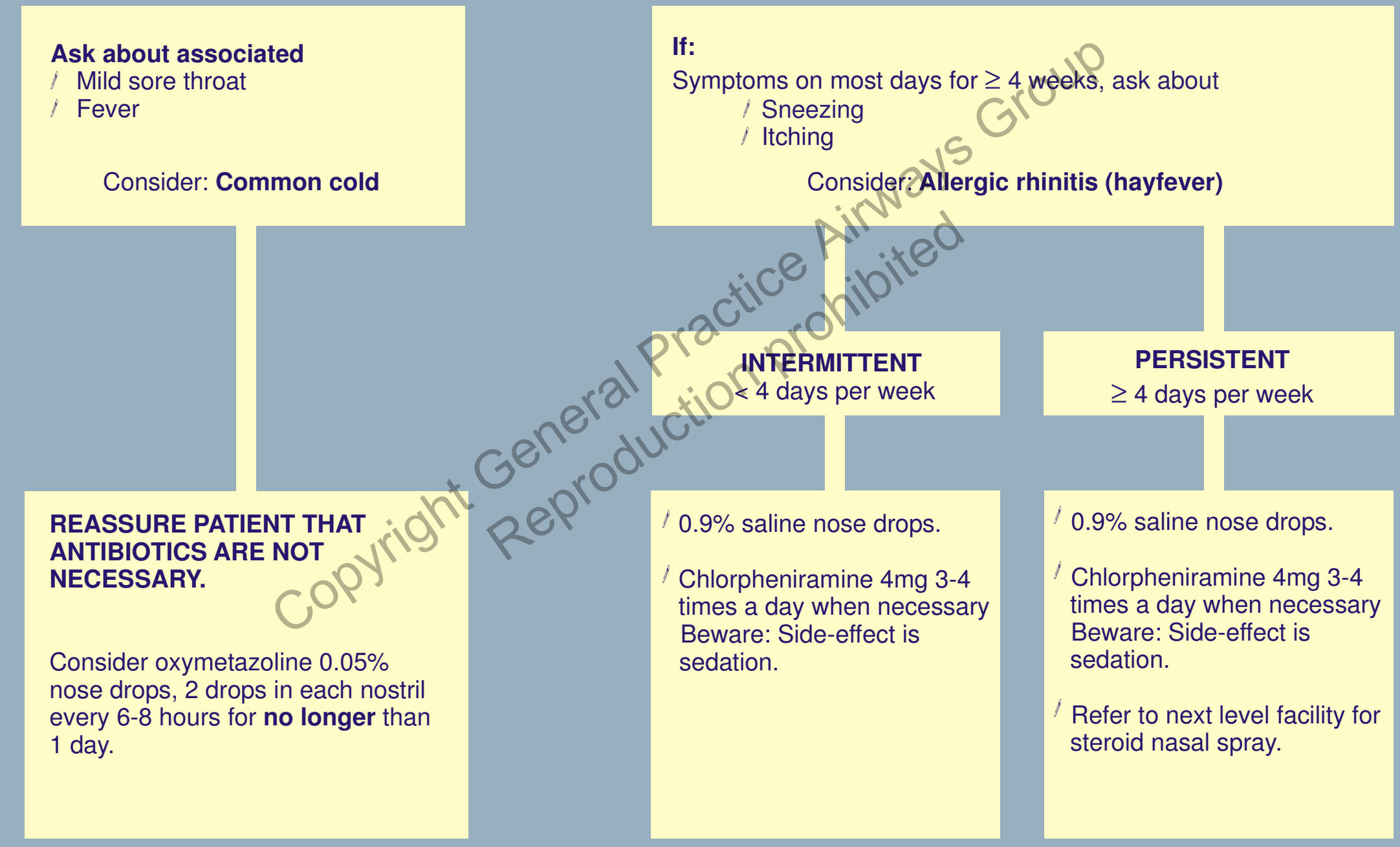




\section{CopyrighILDLY ILL PATIENT WITH PAIN AND/OR TENDERNESS OVER SINUSES: ACUTE SINUSITIS}

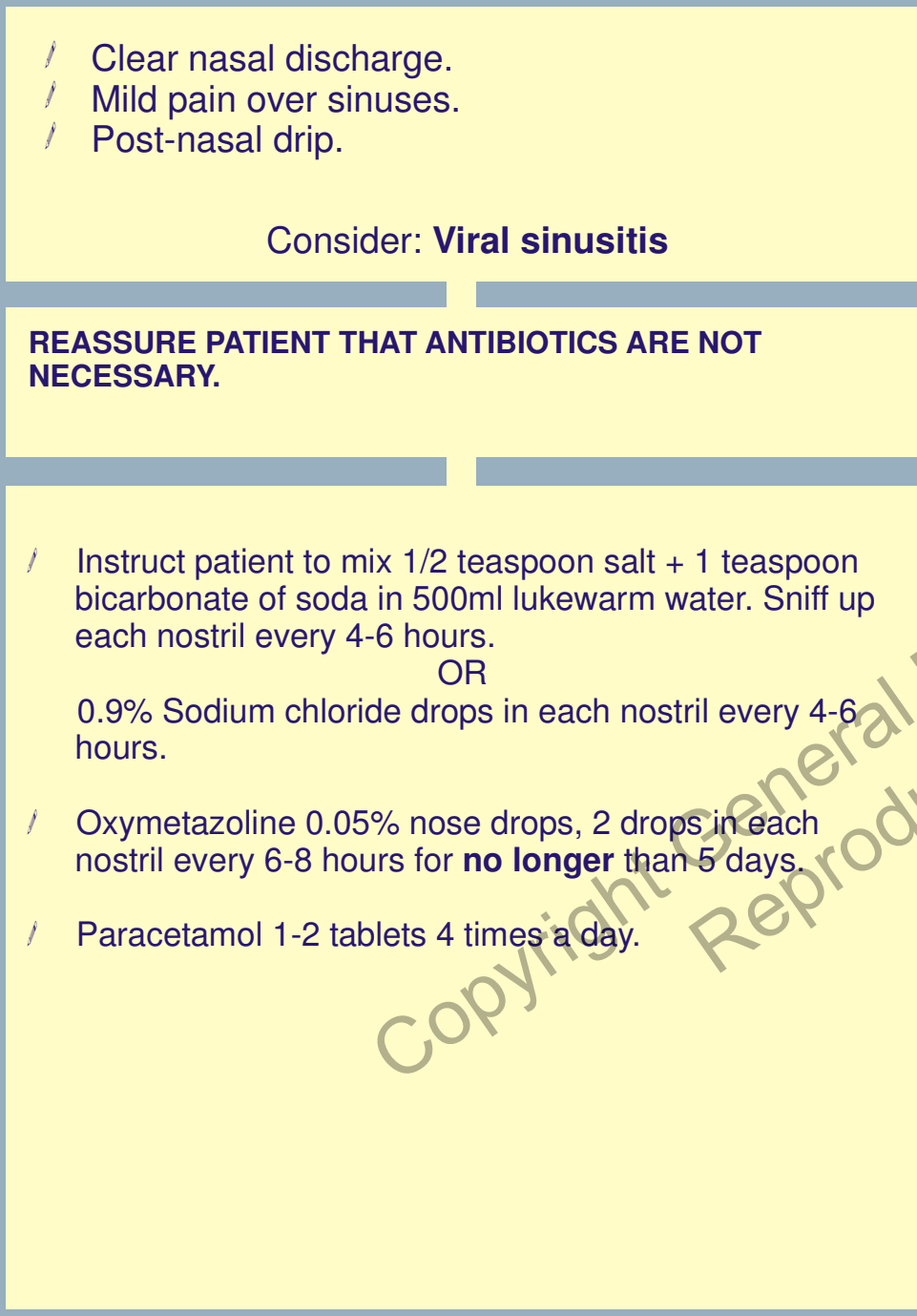

Symptoms $\geq 7$ days.

/ Severe symptoms regardless of duration.

Pussy nasal discharge.

I Face or tooth pain and tenderness.

Consider: Bacterial sinusitis

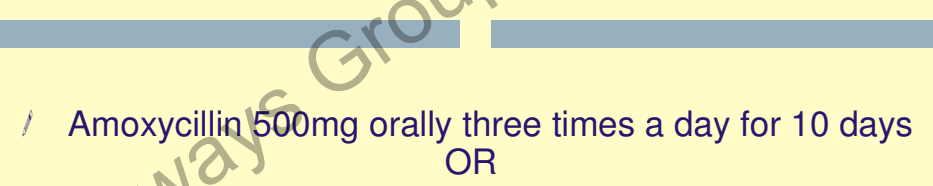

If penicillin-allergic, give cotrimoxazole (Bactrim) 2 tablets $(80 / 400 \mathrm{mg})$ twice a day for 5 days.

Instruct patient to mix $1 / 2$ teaspoon salt +1 teaspoon bicarbonate of soda in $500 \mathrm{ml}$ lukewarm water. Sniff up each nostril every 4-6 hours.

$$
\text { OR }
$$

$0.9 \%$ Sodium chloride drops in each nostril every $4-6$ hours.

Oxymetazoline $0.05 \%$ nose drops, 2 drops in each nostril every 6-8 hours for no longer than 5 days.

f Paracetamol 1-2 tablets 4 times a day.

\section{Refer if:}

Tooth abscess suspected.

Swelling around eye or face.

Failure to respond to medication after 10 days. 


\section{MILDLY ILL PATIENT WITH SORE THROAT:} ACUTE PHARYNGITIS, TONSILLITIS, ORAL CANDIDA
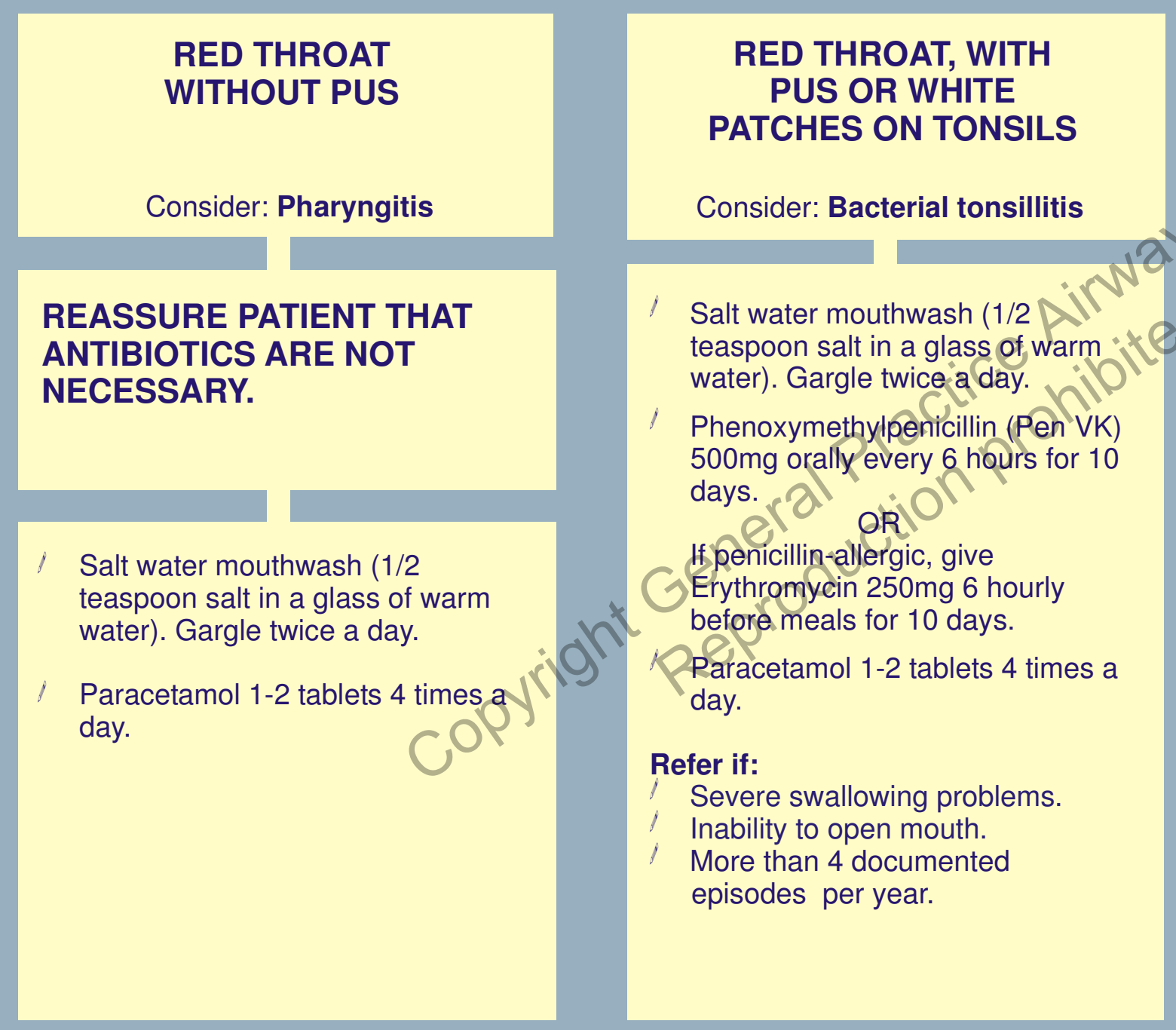

\section{WHITE PATCHES ON CHEEKS, GUMS, TONGUE AND PALATE \\ Consider: Oral candida (thrush)}

Nystatin lozenges $100000 \mathrm{IU}-4$
times a day for 10 days.
OR
Nystatin $100000 \mathrm{IU} / \mathrm{ml} 1-2 \mathrm{ml}$
4 times a day for 10 days.
Exclude HIV infection.
(Go to page 20)

Refer if:
No response to Nystatin within 5
days. Fluconazole to be prescribed
by doctor.
Extensive disease.
Recurrent episodes.




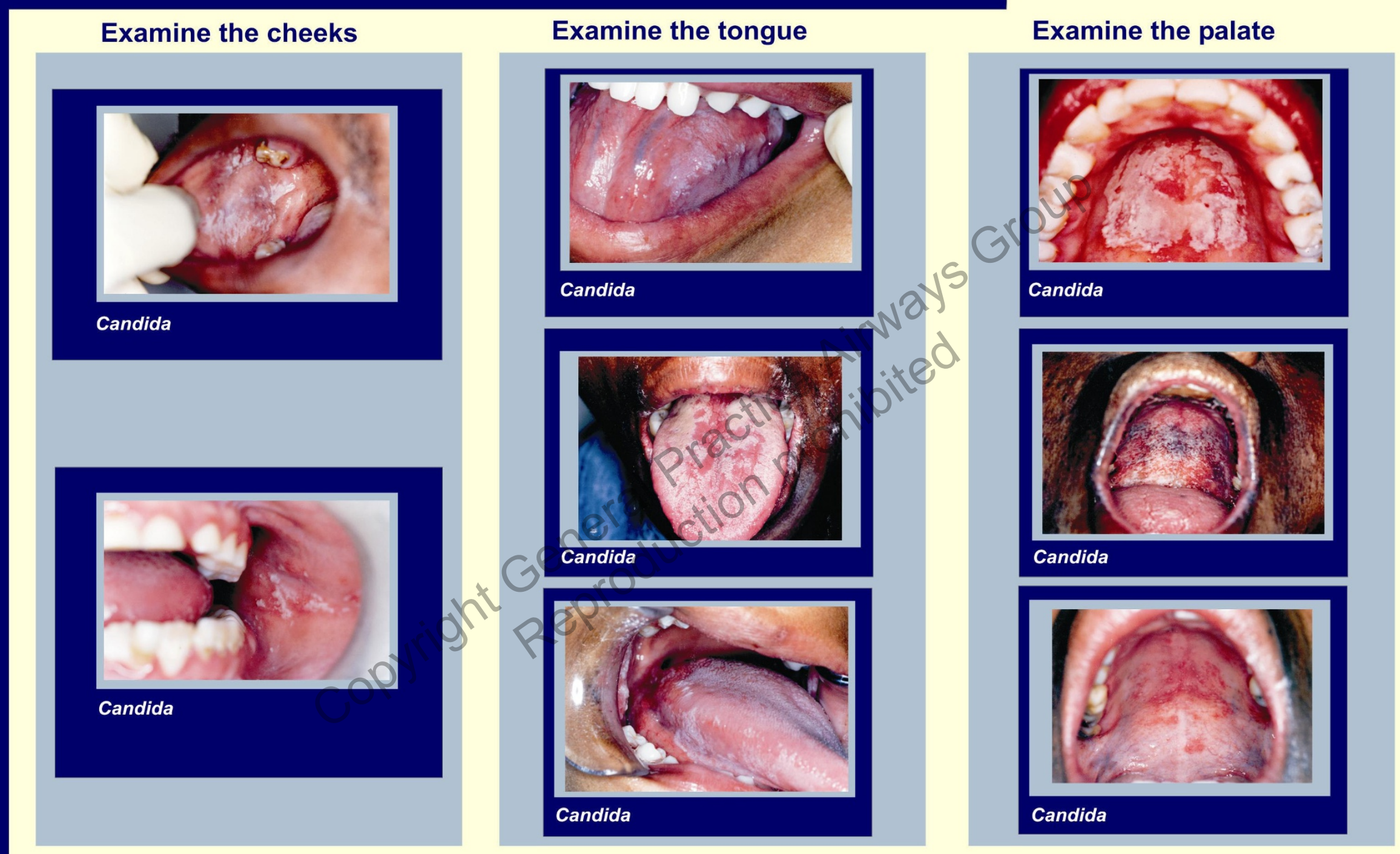




\section{MILDLY ILL PATIENT WITH EAR PROBLEM: ACUTE AND CHRONIC EAR PROBLEMS}

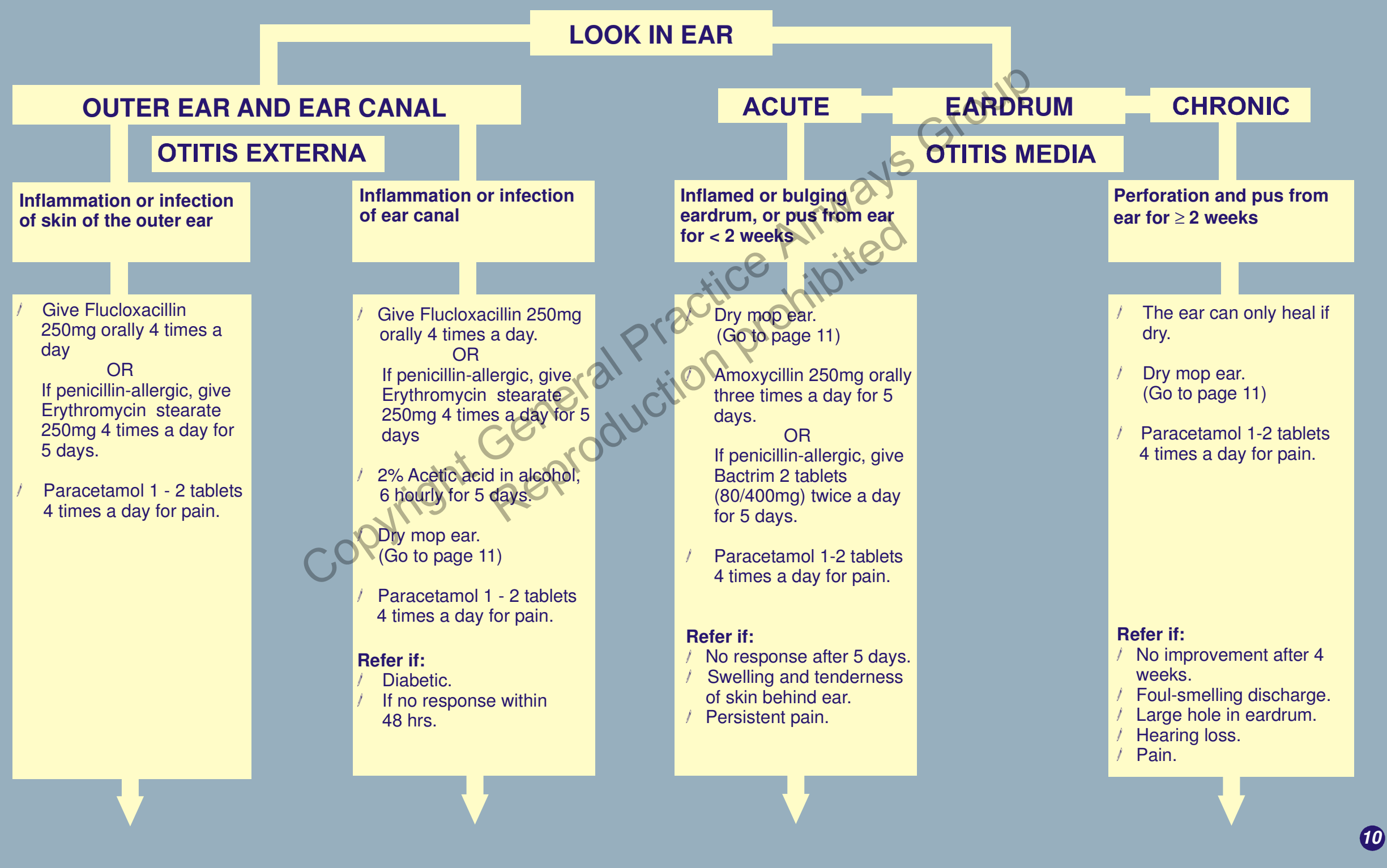




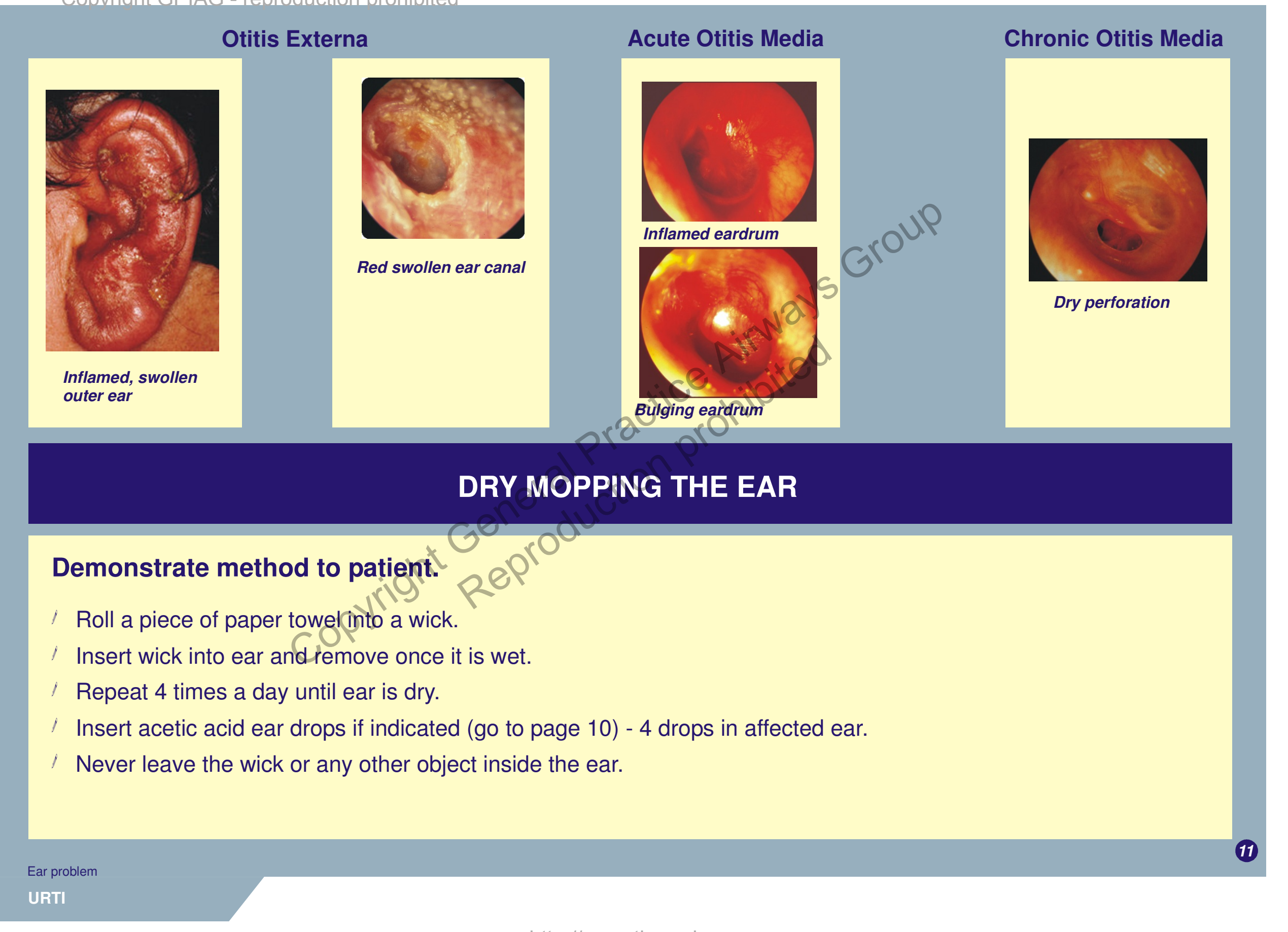




\section{DIAGNOSING OBSTRUCTIVE LUNG DISEASE}

It is not always easy to decide whether a patient has asthma or COPD as the symptoms may be similar, or both diseases may be present.

A few questions may help with the diagnosis.

\section{Ask if: \\ Ask if:}

Symptoms started during childhood or early adulthood.

History of hayfever, eczema and/or allergies.

Family history of asthma

Symptoms only during attacks with periods of normal breathing in between.

Symptoms are usually worse: at night; in the early hours of the morning; during an upper respiratory tract infection or when the weather changes.

Symptoms improve or disappear after using inhaler

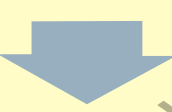

TREAT AS ASTHMA.

REFER TO DOCTOR WITHIN 1 MONTH

Go to page 13
Symptoms started later in life (usually after the age of 35 years). symptoms slowly worsened over a long period of time. Py 8

Long history of daily or frequent cough and sputum production (usually starts long before the onset of shortness of breath).

Short of breath for most of the day, rather than at night or during the early hours of the morning only.

History of heavy smoking eg. more than 20 cigarettes / day for 15 years or more.

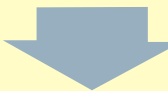

TREAT AS COPD.

REFER TO DOCTOR WITHIN 1 MONTH.

Go to page 14

(If unsure, treat as asthma)

If $\leq 1$ feature of asthma, and no significant history of smoking, consider a cardiac or non-lung cause of breathlessness, especially if associated hypertension, ischaemic heart disease and/or diabetes mellitus. 


\section{MANAGEMENT OF CHRONIC ASTHMA}

The aim of asthma management is to obtain complete control of all features of asthma

Aim for:

1) Minimal (ideally no) daytime and night time symptoms

2) Minimal or no exacerbations (asthma attacks)

3) Minimal need for quick-relief medications

4) No limitations of daily activities

ASSESS CONTROL OF ASTHMA BY ASKING ABOUT DAY AND NIGHT TIME SYMPTOMS
\begin{tabular}{|l|l|l|l|}
\hline LEVEL OF CONTROL & WELL-CONTROLLED & MODERATE CONTROLS & POOR CONTROL \\
\hline $\begin{array}{l}\text { Daytime symptoms per week } \\
\text { Night time symptoms per month }\end{array}$ & $\begin{array}{l}<2 \text { times / week } \\
<2 \text { times / month }\end{array}$ & $\begin{array}{l}2-4 \text { times / week } \\
2-4 \text { times / month } \\
\text { Frequent }\end{array}$ \\
\hline LEVELS OF TREATMENT & LOW (if well-controlled) & MODERATE (if moderate control) & MAXIMUM (if poor control) \\
\hline $\begin{array}{l}\text { Inhaled salbutamol } \\
\text { Inhaled corticosteroids }\end{array}$ & 2 puffs when needed & $\begin{array}{l}2 \text { puffs when needed } \\
\text { May be required 4-6 times per day. }\end{array}$ \\
\hline $\begin{array}{l}\text { Slow-release theophylline } \\
\text { Doctor to initiate }\end{array}$ & & $800-1600$ micrograms / day \\
\hline \begin{tabular}{l} 
Oral prednisone \\
\hline
\end{tabular}
\end{tabular}

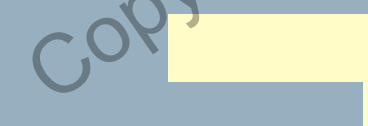

REVIEW EVERY 3 MONTHS
IF COMPLETE CONTROL AT ANY LEVEL OF TREATMENT

Continue current medication.

At next visit, reduce treatment to previous level (step-down)

if control is still complete.

Schedule next appointment.
IF POOR CONTROL AT ANY LEVEL OF TREATMENT

Increase to next level of treatment (step-up).

Consider adding prednisone $40 \mathrm{mg}$ orally once daily for 7 days and reassess in 1 month.

Refer if poor control despite stepping-up. 


\section{MANAGEMENT OF CHRONIC OBSTRUCTIVE PULMONARY DISEASE (COPD)}

The aim of COPD management is to:

Encourage patients to stop smoking in order to prevent worsening of disease. Improve symptoms with inhaled bronchodilators.

Recognise and treat acute exacerbations early.

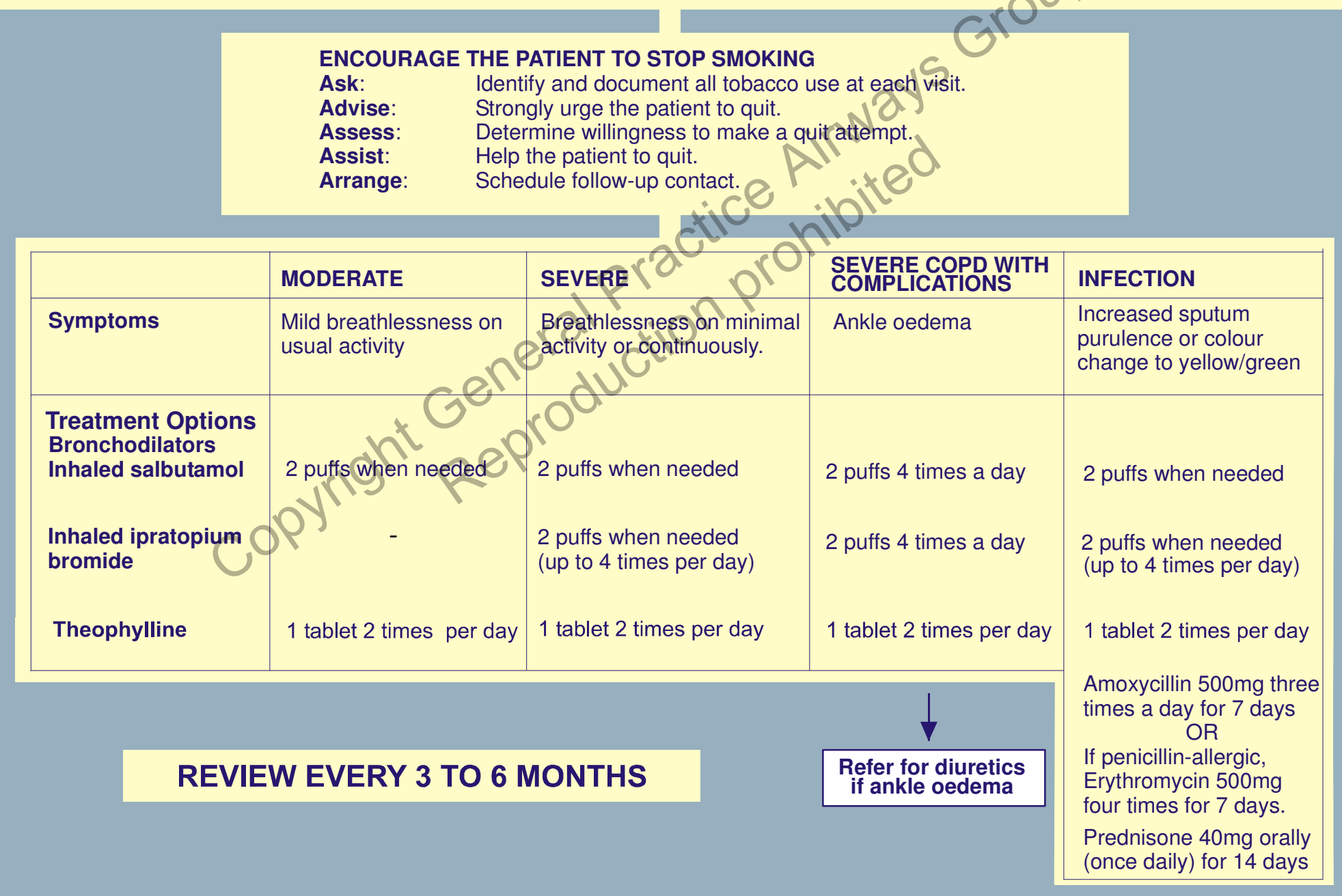




\section{CHRONIC COUGH WITH OR WITHOUT SPUTUM} PRODUCTION; NO BREATHLESSNESS: CHRONIC BRONCHITIS

\section{Usually in heavy smokers, or those with lung damage.}

Daily cough with or without sputum production for months or years.

Usually begins in middle or old age.

/ Heavy occupational (dust, mines, industry) or domestic air pollution (indoor fires or gas stoves) exposure in some.

\section{THE MOST EFFECTIVE TREATMENTIS TO REMOVETHE CAUSE!}

I All patients should be advised to stop smoking.

If possible, avoid domestic pollution, occupational exposure and substance abuse (eg. dagga).

\section{Refer:}

If no history of smoking. 


\section{DIAGNOSING TUBERCULOSIS (TB)*}

\section{SUSPECT TB WHEN:}

I Patient reports cough for $\geq 2$ weeks.

Unintentional weight loss.

Loss of appetite.

Night sweats and fever

Blood-stained sputum

Known HIV-positive or AIDS patients.

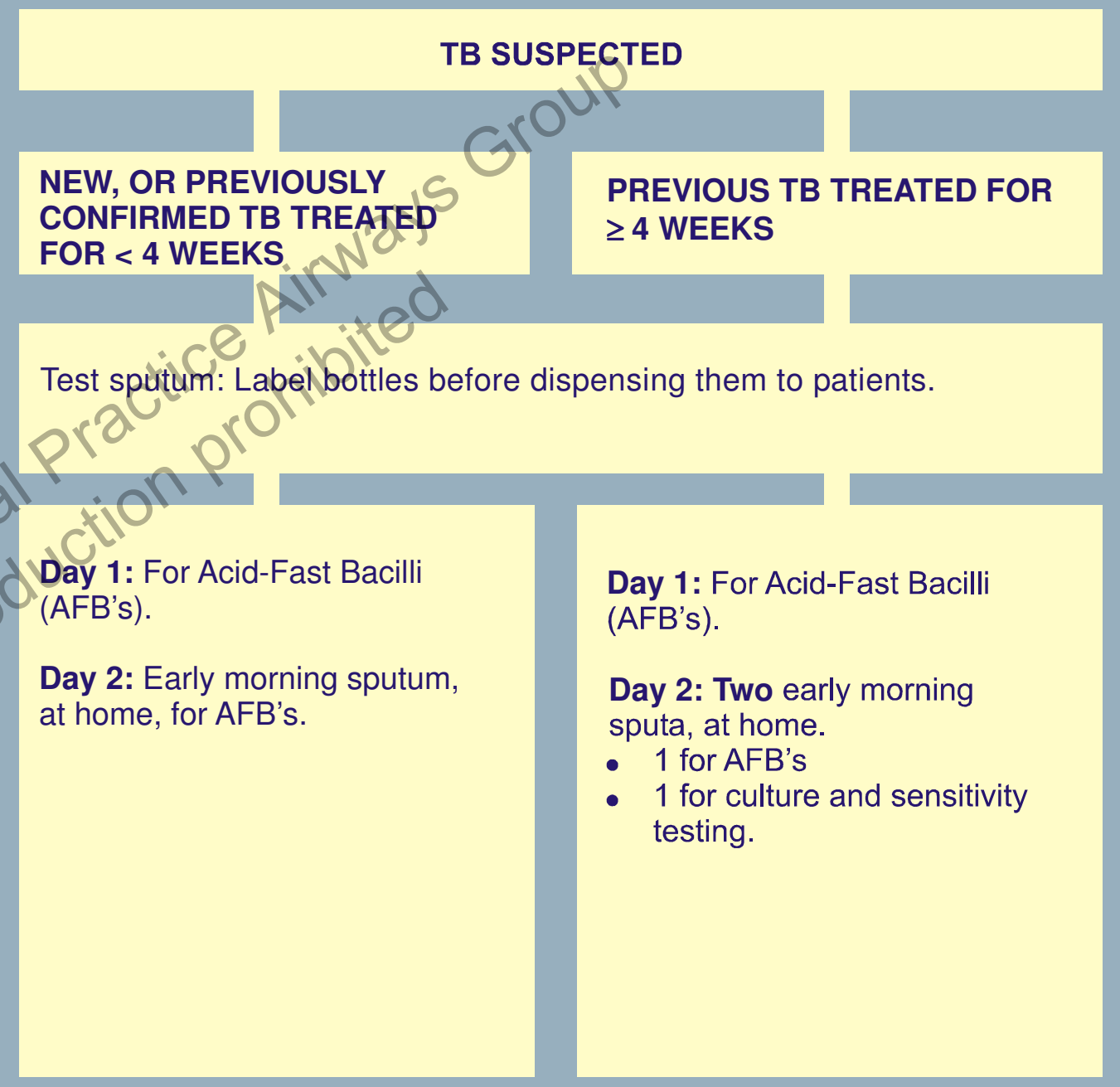

${ }^{*}$ According to the South African Tuberculosis Control Practical Guidelines 2000 


\section{SPUTUM RESULTS}

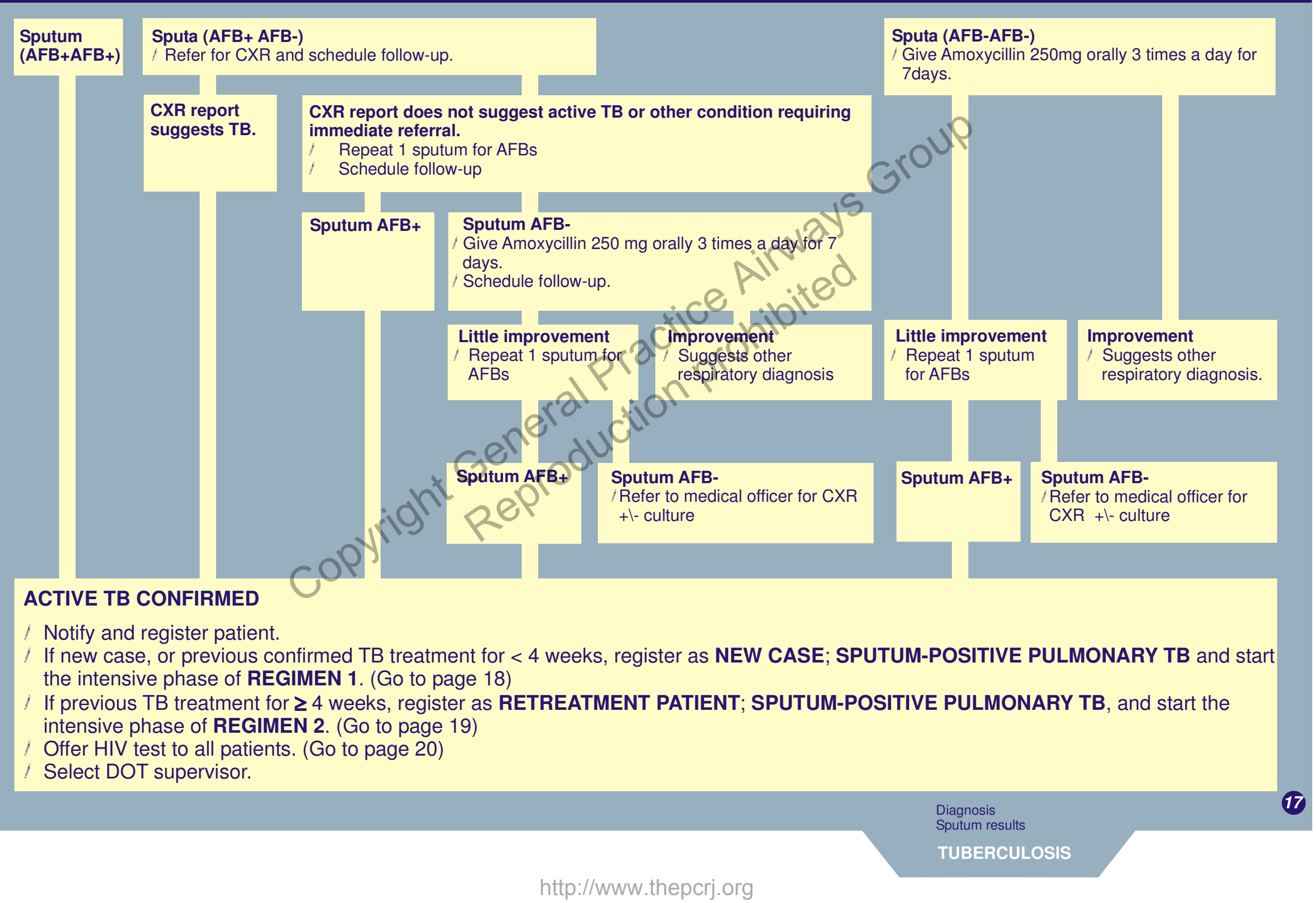




\section{INITIAL TREATMENT FOR REGIMEN ONE}

START INTENSIVE PHASE

Rifampicin/Isoniazid/Pyrazinamide/Ethambutol 120/60/300/200mg (given 5 days a week)
$<50 \mathbf{~ k g}$

4 tablets $\geq 50 \mathrm{~kg}$

5 tablets

At the end of 2 MONTHS of INTENSIVE treatment, take 2 sputa for AFBs. Schedule follow-up.

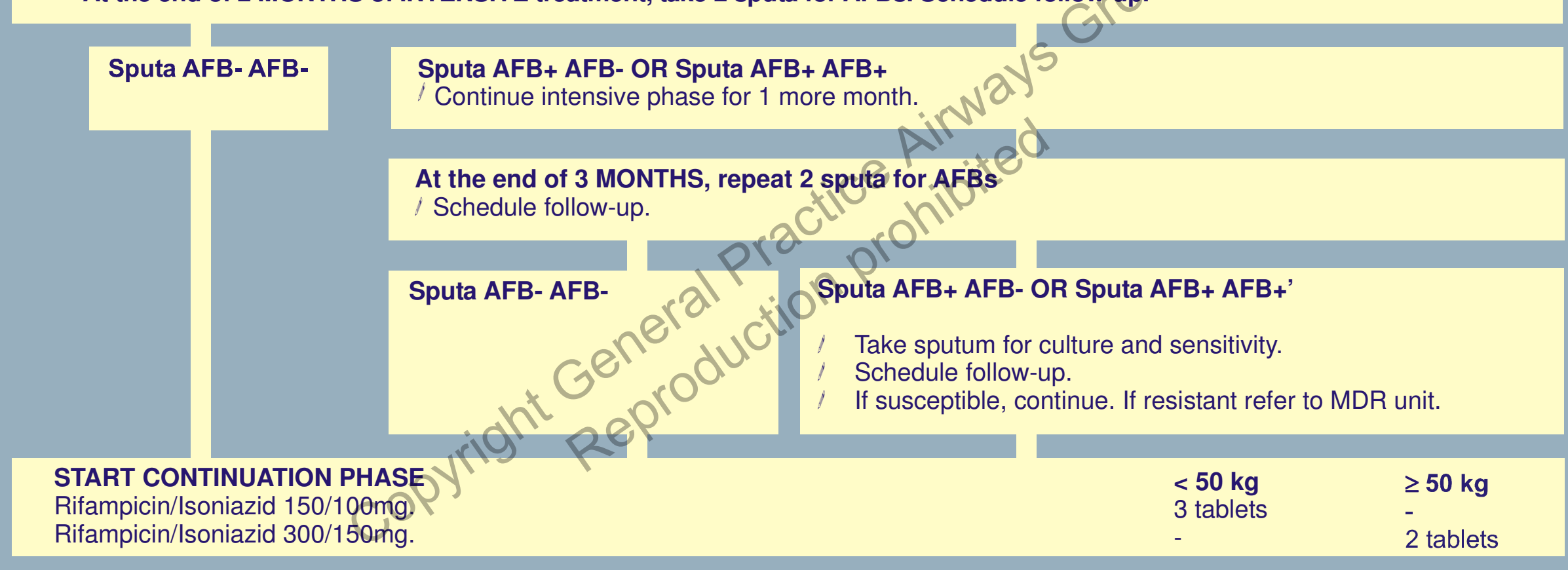

At the end of 5 months of treatment, take 2 sputa for AFBs. Schedule follow-up.

Sputa AFB- AFB- or unable to produce sputum. Stop treatment and register as CURED.

Discharge from TB clinic.

1 Refer HIV-positive patients to the general clinic for further management.
Sputa AFB+ AFB- OR Sputa AFB+ AFB+ Register as TREATMENT FAILURE.

Take sputum for culture and sensitivity

Re-register as a RETREATMENT patient, and refer to follow-up plan for Regimen 2. 


\section{TREATMENT PLAN FOR REGIMEN TWO}

\section{START INTENSIVE PHASE}

Rifampicin/Isoniazid/Pyrazinamide/Ethambutol 120/60/300/200mg (given 5 days a week) PLUS

Streptomycin (given 5 days a week) intramuscularly.

THIRD MONTH

Rifampicin/Isoniazid/Pyrazinamide/Ethambutol 120/60/300/200mg (given 5 days a week) ONLY

\section{$<50 \mathrm{~kg}$ \\ 4 tablets \\ $750 \mathrm{mg}$}

4 tablets

\section{$\geq 50 \mathrm{~kg}$ \\ 5 tablets \\ $1000 \mathrm{mg}$ \\ 5 tablets}

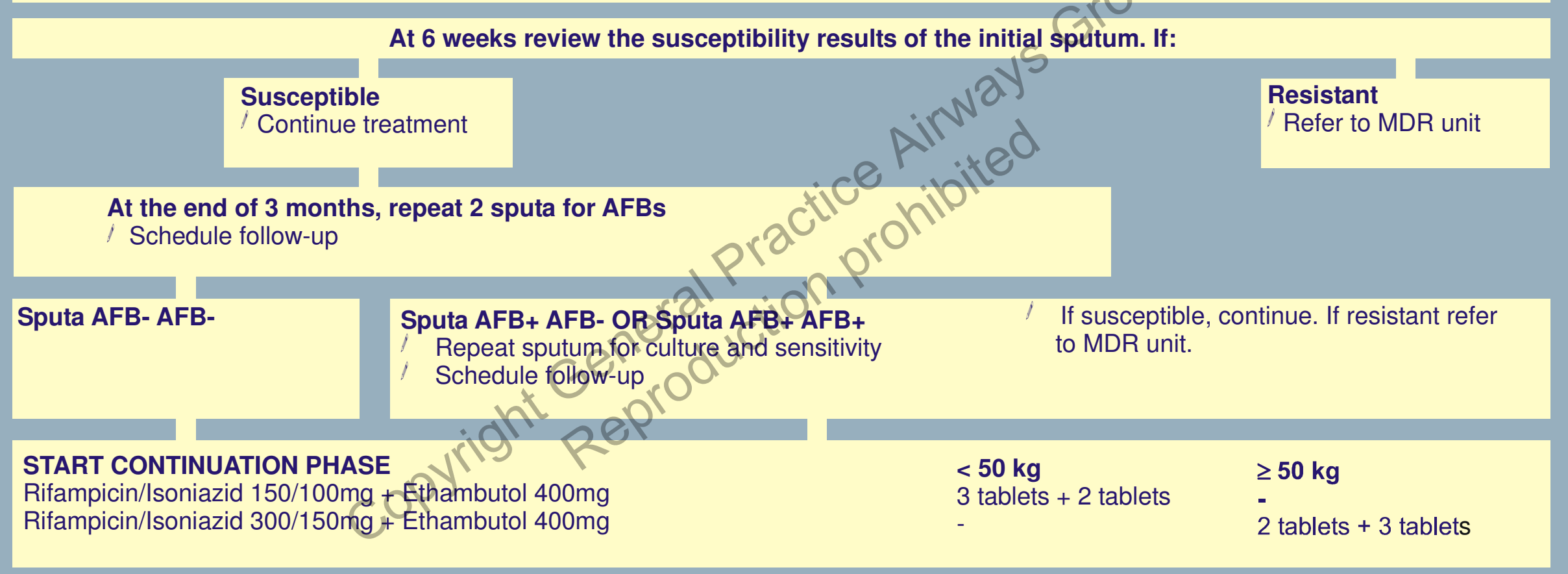

At the end of 7 months of treatment, take 2 sputa for AFBs. Schedule follow-up.

Sputa AFB- AFB- or unable to produce sputum.

Stop treatment and register as CURED.

Discharge from TB clinic.

/ Refer HIV-positive patients to the general clinic for management.
Sputa AFB+ AFB- OR Sputa AFB+ AFB+ / Register as TREATMENT FAILURE.

/ Take sputum for culture and sensitivity.

/ Refer to MDR unit. 


\section{HIV/AIDS}

\section{SUSPECT HIV/AIDS IN ALL WITH THE FOLLOWING:}

\begin{tabular}{l|l} 
TB & Painless swollen glands \\
Recurrent respiratory infections & Long history of diarrhoea \\
Mouth lesions eg. Oral candida & History of engaging in high-risk behaviour (eg. Vaginal, anal or oral \\
Skin infections eg. Herpes Zoster & \\
Severe wighthout a condom) \\
Unexplained fever for $>4$ weeks \\
Sexually transmitted infections
\end{tabular}

\section{LOOK FOR}

White patches in the mouth, which are scratched off with difficulty, causing bleeding (ORAL THRUSH/CANDIDA).

Painful rash with blisters, confined to one part of the body (HERPES ZOSTER)

Bluish-black patches or lumps on skin or mouth (KAPOSI'S SARCOMA).

Evidence of severe loss of weight.

Genital ulcers or discharge.

\section{DO YOU SUSPECT HIVIAIDS ? \\ DOES THE PATIENT REQUEST AN HIV TEST?}

INFORM ABOUT VOLUNTARY CONFIDENTIAL COUNSELLING AND TESTING (VCCT)

Educate patient about HIV/AIDS, methods of transmission and risk factors.

Explain about VCCT:

Who will perform the counselling and the testing

That it is completely voluntary.

That testing is confidential.

How testing is done.

When and how results are given.

What the results means.

If patient agrees to have VCCT, refer to the lay counsellor for testing.

If a lay counsellor is not available, refer to health facility where testing is available.

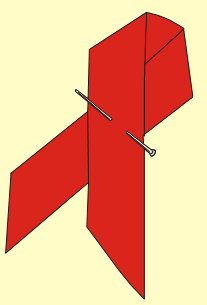




\section{FOLLOW-UP OF KNOWN HIV-POSITIVE PATIENT}

\section{HIV POSITIVE}

Establish a relationship with the patient and encourage regular follow-up. Respect his/her right to confidentiality.

Refer to the lay counsellor should the patient require further counselling.

Encourage safer-sex practices.

Provide medical care at each visit.

Look for and treat HIV-related diseases.

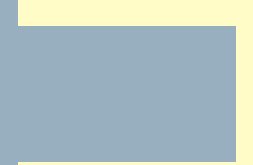

\section{ORAL}

THRUSH/CANDIDA

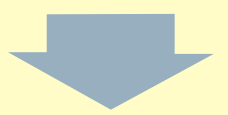

Go to page 9

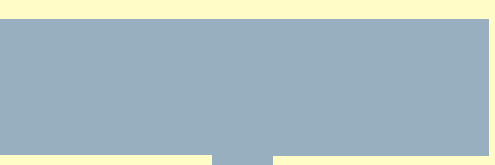

\section{ASYMMETRIC LARGE} GLANDS

For exclusion of extrapulmonary TB.
Refer:
HIV NEGATIVE

Encourage safer sex practices.
ANY OTHER HIV-

RELATED DISEASES

Pro
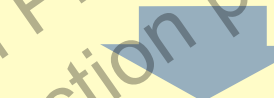

\section{Refer to:}

South African Department of Health booklet:

Recommendations for the prevention and treatment of opportunistic and HIVrelated diseases in adult. (www.http://196.36.153.56 /doh/aids/docs/adult.html)

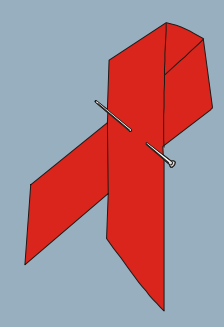

Diagnosis 


\section{WHO IS ELIGIBLE FOR LIFE-LONG COTRIMOXAZOLE (BACTRIM) PROPHYLAXIS? (2 SINGLE STRENGTH TABLETS (80/400MG) PER DAY)}

/ All HIV-infected TB patients

All symptomatic HIV patients (World Health Organisation (WHO) stage $2,3,4)$. Refer below.

If previous diagnosis of Pneumocystis carinii pneumonia.
I Cotrimoxazole (Bactrim) prophylaxis is started at a higherlevel facility.

\section{ADAPTED FROM THE WORLD HEALTH ORGANISATION(WHO) CLINICAL} STAGING FOR HIV INFECTION

\section{STAGE 1}

Without symptoms.

Acute viral illness following HIV infection.

Persistent swollen glands $<2 \mathrm{~cm}$ and symmetrical.

\section{STAGE 2}

Unintentional weight loss.

Minor mouth and skin conditions (dry skin) mouth ulcers, fungal nail infections).

Herpes Zoster within the last 5 years.

Recurrent upper respiratory tract infections (eg. sinusitis).

\section{STAGE 3}

Signifieant unintentional weight loss. Diarrhoea for more than a month.

Fever for more than a month.

Oral thrush/candida.

Pulmonary TB in the last year.

Severe pneumonia or other bacterial infections.

Vaginal candida for more than one month, or poor response to therapy.

\section{STAGE 4}

Chronic weight loss plus diarrhoea or fever. Diagnosed opportunistic infection.

Extra-pulmonary TB.

Kaposi's sarcoma.

HIV dementia.

Diagnosed cancer (eg. Lymphoma).

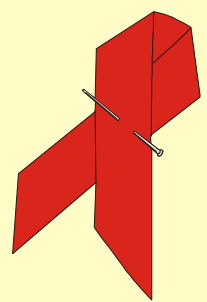

